\title{
Fatty acid signatures reveal fine scale structure of foraging distribution of harbor seals and their prey in Prince William Sound, Alaska
}

\author{
Sara J. Iverson ${ }^{1, *}$, Kathryn J. Frost ${ }^{2}$, Lloyd F. Lowry ${ }^{2}$ \\ ${ }^{1}$ Department of Biology, Dalhousie University, Halifax, Nova Scotia, Canada B3H 4J1 \\ ${ }^{2}$ Alaska Department of Fish and Game, Division of Wildlife Conservation, 1300 College Road, Fairbanks, Alaska 99701, USA
}

\begin{abstract}
Fatty acid signature analysis was used to investigate the diet and the spatial scales of foraging in harbor seals Phoca vitulina richardsi in Prince William Sound (PWS) and elsewhere in the Gulf of Alaska. Blubber samples collected in 1994 and 1995 from 104 harbor seals from PWS, Kodiak Island, and southeast Alaska were analyzed for fatty acid composition. A total of 163 potential prey samples representing 10 taxa were collected and individually analyzed for total fat content and fatty acid composition. Approximately 70 fatty acids and isomers were found in both harbor seals and their prey. Classification and regression tree analysis was used to classify seals and prey according to their fatty acid signatures. Large differences were found in the fatty acid composition of blubber from seals sampled at Kodiak, southeast Alaska and PWS, over a broad geographical scale of 400 to $800 \mathrm{~km}$. Additionally, fatty acid signatures distinguished seals from different regions within PWS, as well as on finescale resolutions of specific haulout sites within 9 to $15 \mathrm{~km}$ of one another These findings suggest that seals forage site-specifically. These conclusions are supported by prey fatty acid patterns, which also differed on similarly small spatial scales within PWS. Not only could prey species such as herring Clupea pallasi and pollock Theragra chalcogramma be differentiated from one another using fatty acid signatures, but they could also be distinguished by size-class and location within PWS, reflecting differences in diet with age and as well as with fine-scale habitat. Results from this study are consistent with both satellite data from tagged harbor seals and stomach content analyses of forage fish species in PWS. Although preliminary, analyses suggest that large herring and pollock, as well as flatfish, may have dominated the diet of seals in southern PWS, whereas diets of seals in northern and eastern PWS may have been comprised more of small size classes of herring and pollock, and perhaps other items such as cephalopods, sandlance Ammodytes hexapterus, cod Gadus macrocephalus, and shrimp. We conclude that fatty acid signature analysis will be an important contribution to understanding marine food webs in estuarine and other marine environments.
\end{abstract}

KEY WORDS: Foraging ecology Fatty acid signatures Harbor seals Fish Spatial scales

\section{INTRODUCTION}

Understanding the foraging ecology of free-ranging marine mammals is critical to evaluating how they function within ecosystems. Pinnipeds (seals, sea lions and fur seals) are widely distributed in temperate and cold oceans of the world. They show a diversity of distributional patterns from highly migratory species such as the harp seal Phoca groenlandica and northern elephant seal Mirounga angustirostris, which occupy

·E-mail: siverson@is.dal.ca the continental shelf and oceanic basins, respectively, to relatively sedentary near-shore species, such as the harbor seal Phoca vitulina, which is thought in general to forage within $50 \mathrm{~km}$ of coastal haulout sites (Pitcher \& McAllister 1981, Thompson \& Miller 1990, Stewart \& Yochem 1994, Bjorge 1995. Frost et al. 1996). Given these differences, we might expect that the spatial scales used during foraging would also differ greatly among species.

Most pinnipeds are top-level predators in ecosystems in which fishes and cephalopods are important prey. As such, a strong relationship might be expected 
between pinniped populations and fish stock abundances, a relationship that may be influenced by commercial fisheries (Beddington et al. 1985). In many parts of the world pinniped populations have increased, as predicted, after protection from over-exploitation (e.g. Olesiuk et al. 1990, Shelton et al. 1995). However, large declines in populations of harbor seals Phoca vitulina richardsi and Steller sea lions Eumetopias jubatus have been documented in the Bering Sea and the Gulf of Alaska (Pitcher 1990, Loughlin et al. 1992). These unanticipated declines have prompted monitoring and assessment of marine mammal and fish population trends, and an evaluation of their relationship to present and past fisheries practices and fish abundance. However, in its analysis of declines in various pinniped populations, a National Research Council study (NRC 1996) highlighted the problem of scale and noted that the mean abundance of pinniped prey at large spatial scales, as determined from fisheries surveys, was unlikely to be relevant to the scale at which seals forage

In Prince William Sound (PWS), a 90 by $130 \mathrm{~km}$ embayment of the Gulf of Alaska, harbor seals are one of the most abundant and widely distributed marine mammals, hauling out and/or breeding at more than 50 sites. Since 1984 harbor seal numbers in PWS have declined by about $60 \%$, with only part of this decline attributable to the 1989 'Exxon Valdez' oil spill (Frost \& Lowry 1994). The decline in harbor seals has not been limited to PWS, but has also occurred in adjacent parts of the Gulf of Alaska (Pitcher 1990). A change in the availability of prey is among the hypothesized causes for this observed decline. Thus, central to evaluating this hypothesis is not only the determination of the diet of harbor seals, but also determination of the way in which individuals use both their habitat and prey on a spatial scale. Indications of how prey species utilize or occupy habitat are also important.

Unfortunately, studies of the feeding ecology of marine mammals face a number of inherent difficulties. With few exceptions prey are consumed below the surface so that direct observations of feeding are usually not possible. Diet studies that use stomach content or fecal analysis involve biases that are reasonably well understood but difficult to avoid (e.g. Jobling \& Brieby 1986, Pierce \& Boyle 1991, Olesiuk 1993, Bowen \& Harrison 1996). Based on such methods, the composition of pinniped diets is known to vary seasonally, geographically, and interannually, presumably reflecting differences in the availability of prey. Although we might expect that changes in the composition of pinniped diets would reflect ecological variation experienced by individuals within and between populations, our understanding of both the spatial scales of foraging behavior of pinnipeds and the impact of scale on diet has received little attention. Satellite and time-depth recorder telemetry can be used to describe at-sea behavior and to make inferences about feeding (e.g. Merrick et al. 1994, Heide-Jørgensen \& Dietz 1995). However, the ability to interpret such data is limited by a lack of understanding of specific feeding methods and of the distribution and characteristics of potential prey.

Recently, fatty acid signature analysis (Iverson 1993) has been advanced to study pinniped diets (Iverson 1995, Iverson et al. 1997). Fatty acids are the largest constituent of lipids and those of carbon chain length 14 or greater are often deposited in animal tissue with minimal modification from diet. Lipids in the marine food web are exceptionally complex and diverse. Owing to various restrictions and specificities in the biosynthesis and modification of fatty acids among different taxonomic groups (e.g. Paradis \& Ackman 1976 , Ackman 1980, Cook 1985, Fraser et al. 1989), many components appear which can be traced to a general or even specific ecological origin. Certain 'indicator' fatty acids (Iverson 1993) exist which are particularly useful in food web studies since they can arise only or mostly from the diet. The use of specific lipids as biological markers has been demonstrated in a number of studies on fish and copepods (Lee et al. 1971, Sargent et al. 1988, Fraser et al. 1989, Klungsoyr et al. 1989, Graeve et al. 1994, St. John \& Lund 1996). Relative proportions of dietary fatty acids have also been shown to be reflected in the fatty acid composition of storage lipids in both captive and free-ranging carnivores (e.g. Reidinger et al. 1985, Rouvinen \& Kiiskinen 1989, Colby et al. 1993, Pond et al. 1995). In seals, ingested fatty acids can be deposited directly into adipose tissue, such that blubber may be a mirror of current diet when a seal is rapidly fattening on a high fat diet (Iverson et al. 1995), or may reflect a longerterm integration of dietary fatty acids and possibly biosynthesized fatty acids at times of reduced intake (Kirsch et al. 1995). Since pinnipeds go through annual periods of extensive fasting and depletion of blubber stores, followed by rapid blubber deposition, sampling of blubber fatty acids in a fattened animal may most closely reflect diet over the past few months of fattening Although methods of fatty acid signature analysis are still being developed, to date the technique has been used both to identify general trophic level of diets and to detect major and minor shifts in diet within populations (Iverson et al. 1997. Smith et al. 1997).

In the present study, we used fatty acid signature analysis to investigate the diet and spatial scales of foraging in harbor seals and their prey in PWS and the Gulf of Alaska. The goals of the study were to determine (1) whether there were differences in the fatty acid composition of harbor seal blubber as a function of 
haulout location within PWS; (2) the fatty acid composition of different PWS prey species and as a function of size-class and location within PWS; (3) whether harbor seals in PWS appear to feed on similar diets as those in other parts of Alaska; and (4) classification rules for estimating the foraging location or habitat use of a given seal using its blubber fatty acid composition, and for identifying a prey species, or its size or location, given the prey fatty acid composition.

\section{METHODS}

Sample collection. Blubber from 104 harbor seals was sampled in 1994 and 1995 and analyzed for fatty acid composition. Most of the seals were caught by entanglement in nets deployed near haulout sites. Blubber core samples were collected from the pelvic region of each seal using sterile $6 \mathrm{~mm}$ biopsy punches and immediately placed in chloroform containing BHT (butylated hydroxytoluene) as an antioxidant and stored frozen $\left(-20^{\circ} \mathrm{C}\right)$ until analysis. Blubber cores $(5$ to $7 \mathrm{~cm}$ ) were consistently taken through the full depth of the blubber layer, excluding that directly nearest $(0.3 \mathrm{~cm})$ to the skin; these deeper areas comprise all the metabolically active sites where deposition of fatty acids occur during periods of fattening (Koopman et al. 1996. Iverson unpubl.). Some blubber samples were also obtained from Alaska Native subsistence hunters in PWS as part of a biosampling program designed to make specimen material from harvested seals available to researchers. Blubber samples obtained in this manner were frozen in airtight plastic bags until they could be shipped to a laboratory where they were placed in chloroform/BHT and frozen.

Seals were sampled in PWS ( $n=82)$ and from other areas of the Gulf of Alaska: Kodiak Island $(n=8)$ and Southeast Alaska (SEA, $n=14$ ). Within PWS (see Fig. 1), seals were grouped by sampling locality into 3 general regions: southern PWS (S-PWS, $n=63$, comprising animals from Channel Island, $n=20$, Little Green Island, $\mathrm{n}=10$, Port Chalmers, $\mathrm{n}=21$, Stockdale Harbor, $\mathrm{n}=10$, and Applegate Rocks, $n=2$ ), northcentral/northwest PWS (N-PWS, $n=9$, comprising animals from Long Bay, Glacier Bay, Fairmount Island, Outpost Island, Dutch Group, and Lone Island), and eastern PWS (E-PWS, $\mathrm{n}=10$, comprising animals from Port Fidalgo and Port Gravina).

Potential prey species of harbor seals were collected from fishing trawls at PWS at various locations during 1994 and 1995 and stored frozen in airtight bags until analysis. A total of 163 individual prey representing 10 taxa (herring Clupea pallasi, walleye pollock Theragra chalcogramma, Pacific cod Gadus macrocephalus, tomcod Microgadus proximus, rainbow smelt Osmerus mordax, copper rockfish Sebastes caurinus, sandlance Ammodytes hexapterus, yellowfin sole Limanda aspera, octopus Octopus sp., and a mixture of small squid and shrimp Pandalus sp.) were analyzed for total fat content and fatty acid composition. Prey collection was in part opportunistic, and samples of various size classes from several areas of PWS were collected only for herring $(n=77)$ and pollock $(n=44)$; hence more detailed analyses of these species were possible.

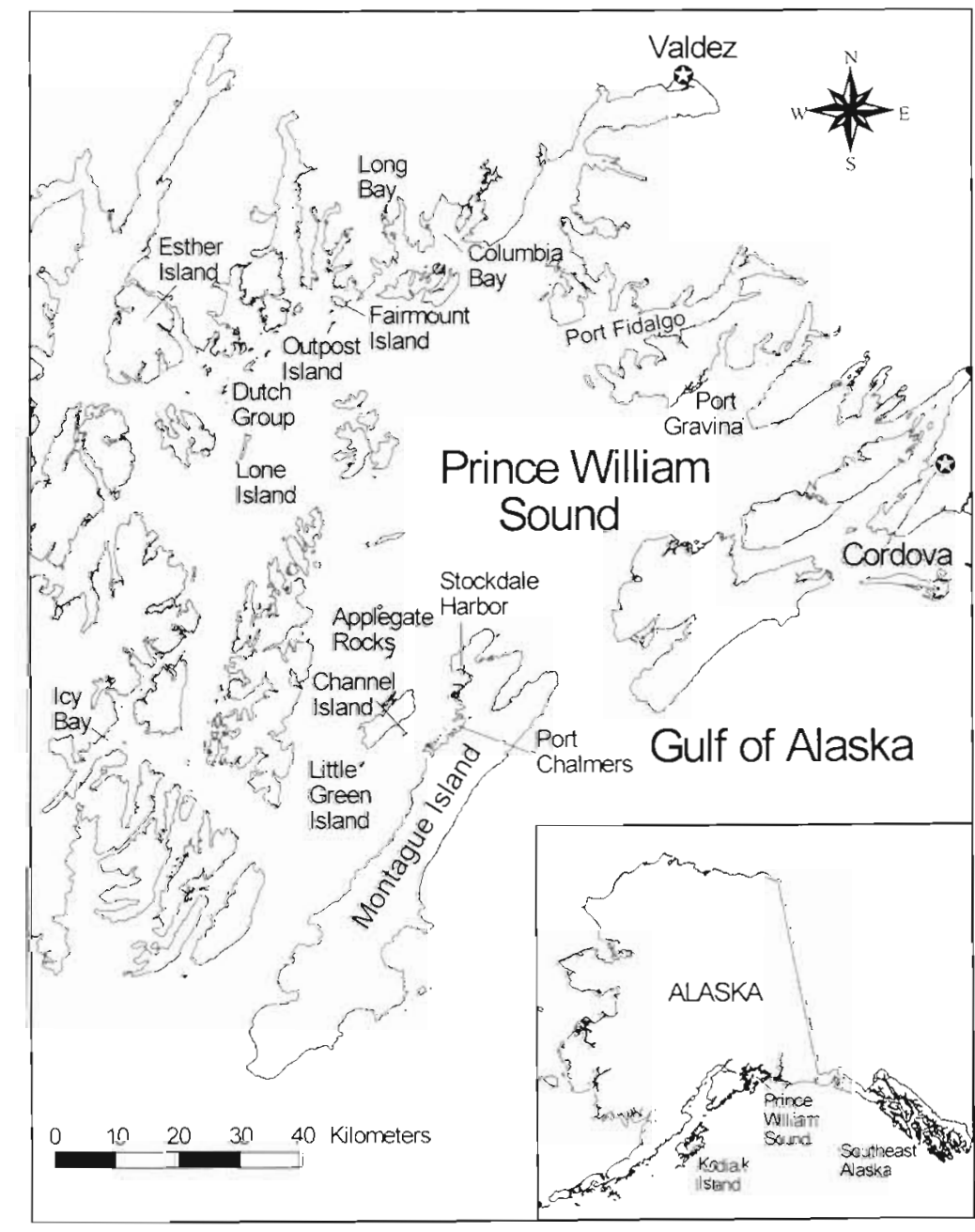

Fig. 1. Prince William Sound, Alaska, showing major locations of harbor seals and prey sampled 
Sample analysis. Lipid was extracted from harbor seal blubber samples according to the method of Folch et al. (1957) as modified by Iverson (1988). After recording length and mass, each whole prey was ground individually and lipids were quantitatively extracted in duplicate aliquots using a modified Bligh \& Dyer method (Bligh \& Dyer 1959); fat content of individuals was expressed as an average of the 2 duplicates. Fatty acid methyl esters were prepared directly from $\geq 100 \mathrm{mg}$ of the pure extracted lipid (filtered and dried over anhydrous sodium sulfate), using $1.5 \mathrm{ml} 8 \%$ boron trifluoride in methanol $(\mathrm{v} / \mathrm{v})$ and $1.5 \mathrm{ml}$ hexane, capped under nitrogen, and heated at $100^{\circ} \mathrm{C}$ for $1 \mathrm{~h}$. Fatty acid methyl esters were extracted into hexane, concentrated, and brought up to volume (50 $\mathrm{mg} \mathrm{ml}^{-1}$ ) with high purity hexane. This method of transesterification, as employed in our lab with fresh reagents, was routinely tested and found to produce identical results to that using Hilditch reagent (0.5 $\mathrm{N} \mathrm{H}_{2} \mathrm{SO}_{4}$ in methanol).

Duplicate analyses of fatty acid methyl esters were performed on samples using temperature-programmed gas liquid chromatography according to Iverson (1988) and Iverson et al. (1992), on a Perkin Elmer Autosystem II Capillary FID gas chromatograph fitted with a $30 \mathrm{~m} \times$ $0.25 \mathrm{~mm}$ i.d. column coated with $50 \%$ cyanopropyl polysiloxane $(0.25 \mu \mathrm{m}$ film thickness; J\&W DB-23; Folsom, CA, USA) and linked to a computerized integration system (Turbochrom 4 software, PE Nelson). Identifications of fatty acids and isomers were determined from the following sources: known standard mixtures (Nu Check Prep., Elysian, MN, USA), silver-nitrate (argentation) chromatography (Iverson 1988), and several secondary external reference standard mixtures composed of natural mixtures of fatty acids from several fish and seal oils which had been identified by chemical degradative and spectroscopic procedures including hydrogenation and GC-mass spectrometry performed in the laboratory of R. G. Ackman (e.g. Ackman \& Eaton. 1971; reviewed in Ackman 1994). Individual fatty acids are expressed as weight percent of total fatty acids after employing mass response factors relative to 18:0. Theoretical relative response factors (Ackman 1991) were used for this purpose, with minor adjustments made after tests with accurate quantitative standard mixtures (Nu Check Prep., Elysian, MN, USA). GC columns were kept in good condition throughout the study by changing septa daily, cleaning the injector liner regularly, and by use of a guard column. All sample chromatograms and identifications were individually checked daily and freshly made quantitative standard mixtures were rerun several times weekly to determine any column deterioration or re-programming of GC necessary. Fatty acids are expressed as weight percent of total fatty acids and are designated by shorthand IUPAC nomenclature of carbon chain length:number of double bonds and location $(n-x)$ of the double bond nearest the terminal methyl group. Ali data are presented as mean $\pm \mathrm{SD}$, unless otherwise indicated.

Data analysis and interpretation. Fatty acid data were analyzed using classification and regression trees (CART) in S-plus (Venables \& Ripley 1994) according to methods described in Iverson et al. (1997) and Smith et al. (1997). CART is a non-parametric multivariate technique for classifying data (Clark \& Pregibon 1992) and has recently been applied to the analysis of fatty acid signatures, which require the interpretation of complicated patterns containing more than 60 variables (fatty acids) per observation (Iverson et al. 1997. Smith et al. 1997). In overview, CART proceeds by recursively partitioning data into 2 or more groups based on a series of dichotomous splits and screens the entire set of fatty acids to choose a subset that is best used to classify data into relatively homogeneous groups. CART uses a series of algorithms which automatically select the 'best' variable to split data into 2 named groups ('nodes') that are as different as possible. The deviance of a node is then a measure of the homogeneity of the observations that fall into each side of that node. The CART algorithm begins at the root node by considering all possible ways to split the data [i.e. all variables (fatty acids) and all possible splitting points within each variable] and chooses that split that maximizes the difference at that node. The observations (seals or prey) in that split are then sent down 1 of 2 branches. This splitting is continued in a tree-like form and occurs until 1 of 2 stopping criteria (based on a minimum number of observations in a node or a minimum deviance of a node relative to the root node) is met. Tree growth (splitting) ends at a terminal node where a classification is made and the associated misclassification rate (number of observations not correctly classified in the node) is given. The distribution of the data at each non-terminal node can then be viewed in the form of tree box plots, which successively remove the effect of the previous split(s) and allows examination of the splitting point at each node.

The fatty acids and splitting points in the tree are selected by maximizing the change in deviance between the root node and subsequent nodes. To examine how robust the resulting trees were to this classification, we also examined other fatty acids that contributed to large changes in deviance. We then used these fatty acids, particularly those known to be indicative of diet differences, to initiate the tree. The efficiencies of the corresponding trees and competing fatty acids were then compared to the initial tree.

CART analysis has advantages over other multivariate methods such as discriminant analy sis for several reasons. Although both CART and chscriminant analysis are aimed at deriving well-defined rules for allocat- 
ing new observations in the future (Johnson \& Wichern 1992), discriminant analysis requires a statistical distribution assumption, it can consider no more than $n-1$ variables where $n$ is the number of animals sampled, and it requires subjective selection of variables where the number of variables exceeds the number of samples and thus information may be lost in the process. In contrast, CART is non-parametric and unaffected by spurious correlations; it can consider any number of variables, and variable selection is not subjective (i.e. it is based on a statistical criterion). CART may be especially useful in cases where the number of variables are particularly large relative to the sample size, such as with marine fatty acids. Because discriminant or principle components analysis have previously been used to analyze fatty acid patterns (e.g. Grahl-Nielsen \& Mjaavateen 1991, Armstrong et al. 1994, Navarro et al. 1995), we compared results of our CART classifications with that of linear discriminant analysis in S-Plus (Venables \& Ripley 1994), choosing several subsets of the fatty acids and using unbiased covariance matrices (e.g. Smith et al. 1997). Individual comparisons of specific fatty acids using ANOVA were used in only limited situations, since if all approximately 70 variables were compared, differences could arise from chance alone.

\section{RESULTS}

\section{Harbor seal fatty acids-Gulf of Alaska}

Approximately 70 fatty acids and their isomers were routinely identified in all harbor seal blubber samples and used in all CART analyses; however only those found at levels $\geq 0.5 \%$ in seals and/or prey are presented here to reduce the size of tables (see Iverson \& Frost 1996 for a complete list of components identified). Large differences were apparent in levels of many components among seals from Kodiak, PWS, and SEA, as well as among regions within PWS (Table 1).

Table 1. Fatty acid composition of harbor seal blubber $(n=104)$. Values (excluding ratios) are mean weight percent \pm SD of fatty acids ( 32 out of 72 ) present at levels $\geq 0.5 \%$ in harbor seal blubber and/or prey species (see Table 3 )

\begin{tabular}{|c|c|c|c|c|c|}
\hline \multirow{2}{*}{ Fatty acid } & \multirow{2}{*}{$\begin{array}{c}\text { Southern PWS } \\
n=63\end{array}$} & \multirow{2}{*}{$\begin{array}{c}\text { Prince William Sound - } \\
\text { Northern PWS } \\
n=9\end{array}$} & \multirow[b]{2}{*}{$\begin{array}{c}\text { Eastern PWS } \\
n=10\end{array}$} & \multirow{2}{*}{$\begin{array}{l}\text { Gulf of Alaska } \\
\text { Kodiak Island } \\
n=8\end{array}$} & \multirow[b]{2}{*}{$\begin{array}{c}\text { SEA } \\
\mathrm{n}=14\end{array}$} \\
\hline & & & & & \\
\hline $14: 0$ & $4.76 \pm 1.00$ & $3.96 \pm 0.58$ & $4.38 \pm 0.73$ & $4.13 \pm 0.51$ & $3.09 \pm 0.62$ \\
\hline $14: 1 n-5$ & $1.76 \pm 0.62$ & $2.33 \pm 0.72$ & $1.98 \pm 0.34$ & $2.12 \pm 0.88$ & $1.69 \pm 0.62$ \\
\hline $15: 0$ & $0.25 \pm 0.04$ & $0.22 \pm 0.03$ & $0.27 \pm 0.06$ & $0.22 \pm 0.03$ & $0.21 \pm 0.04$ \\
\hline Iso 16 & $0.06 \pm 0.03$ & $0.07 \pm 0.01$ & $0.07 \pm 0.01$ & $0.07 \pm 0.01$ & $0.06 \pm 0.01$ \\
\hline $16: 0$ & $8.47 \pm 1.56$ & $7.78 \pm 1.03$ & $9.46 \pm 1.37$ & $7.66 \pm 1.13$ & $6.71 \pm 1.68$ \\
\hline $16: 1 n-11$ & $0.64 \pm 0.19$ & $0.54 \pm 0.11$ & $0.53 \pm 0.26$ & $0.67 \pm 0.10$ & $0.50 \pm 0.16$ \\
\hline $16: 1 n-9$ & $0.44 \pm 0.07$ & $0.56 \pm 0.06$ & $0.54 \pm 0.09$ & $0.45 \pm 0.07$ & $0.50 \pm 0.07$ \\
\hline $16: 1 n-7$ & $17.41 \pm 3.91$ & $21.87 \pm 4.13$ & $20.46 \pm 2.87$ & $19.52 \pm 4.50$ & $18.97 \pm 4.67$ \\
\hline $16: 2 n-4$ & $0.27 \pm 0.19$ & $0.15 \pm 0.10$ & $0.18 \pm 0.14$ & $0.09 \pm 0.02$ & $0.09 \pm 0.03$ \\
\hline $16: 3 n-6$ & $0.35 \pm 0.21$ & $0.41 \pm 0.11$ & $0.38 \pm 0.19$ & $0.60 \pm 0.08$ & $0.61 \pm 0.16$ \\
\hline $17: 0$ & $0.14 \pm 0.07$ & $0.11 \pm 0.03$ & $0.18 \pm 0.09$ & $0.10 \pm 0.04$ & $0.09 \pm 0.03$ \\
\hline $17: 1$ & $0.37 \pm 0.20$ & $0.44 \pm 0.05$ & $0.50 \pm 0.09$ & $0.42 \pm 0.06$ & $0.50 \pm 0.16$ \\
\hline $16: 4 n-1$ & $0.21 \pm 0.18$ & $0.13 \pm 0.12$ & $0.09 \pm 0.11$ & $0.33 \pm 0.11$ & $0.29 \pm 0.11$ \\
\hline 18:0 & $0.93 \pm 0.23$ & $0.82 \pm 0.19$ & $1.09 \pm 0.25$ & $0.83 \pm 0.19$ & $0.80 \pm 0.15$ \\
\hline $18: 1 n-11$ & $2.49 \pm 1.05$ & $1.34 \pm 0.58$ & $1.45+0.53$ & $1.37 \pm 0.43$ & $1.34 \pm 0.49$ \\
\hline $18: 1 n-9$ & $22.64 \pm 4.70$ & $26.15 \pm 5.66$ & $26.46 \pm 6.96$ & $25.03 \pm 4.62$ & $28.83 \pm 5.43$ \\
\hline $18: 1 n-7$ & $3.74 \pm 0.66$ & $4.61 \pm 0.70$ & $4.42 \pm 0.61$ & $4.42 \pm 1.02$ & $4.97 \pm 0.75$ \\
\hline $18: 1 n-5$ & $0.47 \pm 0.04$ & $0.43 \pm 0.05$ & $0.44 \pm 0.06$ & $0.43 \pm 0.05$ & $0.34 \pm 0.07$ \\
\hline $18: 2 n-6$ & $1.08 \pm 0.15$ & $1.03 \pm 0.12$ & $1.02 \pm 0.17$ & $1.00 \pm 0.20$ & $1.05 \pm 0.31$ \\
\hline $18: 3 n-3$ & $0.72 \pm 0.15$ & $0.56 \pm 0.12$ & $0.58 \pm 0.16$ & $0.62 \pm 0.17$ & $0.54 \pm 0.20$ \\
\hline $18: 4 n-3$ & $1.09 \pm 0.31$ & $0.74 \pm 0.11$ & $0.74 \pm 0.18$ & $0.87 \pm 0.23$ & $0.68 \pm 0.15$ \\
\hline $20: 1 n-11$ & $6.01 \pm 2.17$ & $2.46 \pm 0.84$ & $2.39 \pm 0.42$ & $4.45 \pm 1.70$ & $2.50 \pm 1.26$ \\
\hline $20: 1 n-9$ & $1.70 \pm 0.37$ & $1.32 \pm 0.18$ & $1.28 \pm 0.26$ & $1.45 \pm 0.43$ & $1.97 \pm 0.75$ \\
\hline Ratio 20:1 $1^{\text {a }}$ & $3.48 \pm 0.71$ & $1.89 \pm 0.68$ & $1.93 \pm 0.39$ & $3.04 \pm 0.51$ & $1.23 \pm 0.47$ \\
\hline $20: 1 n-7$ & $0.24 \pm 0.11$ & $0.21 \pm 0.10$ & $0.27 \pm 0.16$ & $0.24 \pm 0.13$ & $0.25 \pm 0.08$ \\
\hline $20: 4 n-6$ & $0.61 \pm 0.26$ & $0.61 \pm 0.16$ & $0.74 \pm 0.39$ & $0.59 \pm 0.23$ & $0.49 \pm 0.12$ \\
\hline $20: 4 n-3$ & $0.63 \pm 0.22$ & $0.52 \pm 0.15$ & $0.47 \pm 0.18$ & $0.49 \pm 0.18$ & $0.56 \pm 0.26$ \\
\hline $20: 5 n-3$ & $4.63 \pm 1.18$ & $4.50 \pm 1.12$ & $4.11 \pm 1.21$ & $5.38 \pm 1.58$ & $5.77 \pm 1.20$ \\
\hline $22: 1 n-11$ & $1.73 \pm 1.33$ & $0.35 \pm 0.18$ & $0.58 \pm 0.36$ & $0.90 \pm 0.55$ & $0.32 \pm 0.18$ \\
\hline $22: 1 n-9$ & $0.15 \pm 0.06$ & $0.13 \pm 0.11$ & $0.14 \pm 0.10$ & $0.12 \pm 0.09$ & $0.12 \pm 0.09$ \\
\hline Ratio $22: 1^{\mathrm{d}}$ & $11.11 \pm 4.87$ & $3.95 \pm 3.07$ & $4.96 \pm 2.64$ & $8.86 \pm 3.43$ & $2.90 \pm 1.07$ \\
\hline $22: 5 n-3$ & $3.71 \pm 1.52$ & $3.26 \pm 1.17$ & $3.13 \pm 1.34$ & $3.89 \pm 1.36$ & $4.52 \pm 1.22$ \\
\hline $22: 6 n-3$ & $8.17 \pm 2.75$ & $8.97 \pm 3.05$ & $7.64 \pm 2.91$ & $8.07 \pm 2.59$ & $8.26 \pm 2.68$ \\
\hline $24: 1 n-9$ & $0.09 \pm 0.09$ & $0.03 \pm 0.02$ & $0.11 \pm 0.11$ & $0.05 \pm 0.02$ & $0.04 \pm 0.02$ \\
\hline
\end{tabular}


Of note in all seals was the large proportion of 20:1n-11 relative to the isomer $20: 1 n-9$, as well as its variability among groups. Isomers $(n-11$ and $n-9)$ of the other long-chain monounsaturate, 22:1, were also highly variable among groups of seals (Table 1). Thus, we formed 2 additional components to express the relationships between these isomers. While this may place some additional emphasis on these components, these isomers are particularly informative fatty acids since they can arise only or mostly from diet (reviewed in Iverson 1993, see also 'Discussion'). A ratio of the $n-11$ and $n-9$ isomers was calculated for both $20: 1$ and 22:1 and included in the list of fatty acids (Table 1) and in the data sets used by CART. These 4 components and their ratios illustrate some of the differences between the seal groups (Fig. 2). Within PWS, southern seals differed from northern and eastern seals in most isomers and ratios of 20:1 and 22:1 Kodiak differed from most PWS and SEA seals in these components, but tended to share more similarities with southern PWS animals. SEA seals differed from PWS seals, but tended to be more similar to some of the northern and eastern PWS animals (Fig. 2).

The results of CART analysis confirmed the general observations of differences among groups of seals (Fig. 3) Using the ratio of 20:1, which exhibited the greatest deviance between groups at the root node (Fig. 4), CART correctly classified $92 \%$ of the seals according to their geographical location at sampling. Most animals from northern PWS and eastern PWS and all SEA animals were sent down the left node and were then separated from each other with only 1 out of 27 misclassifications, while most southern PWS and all

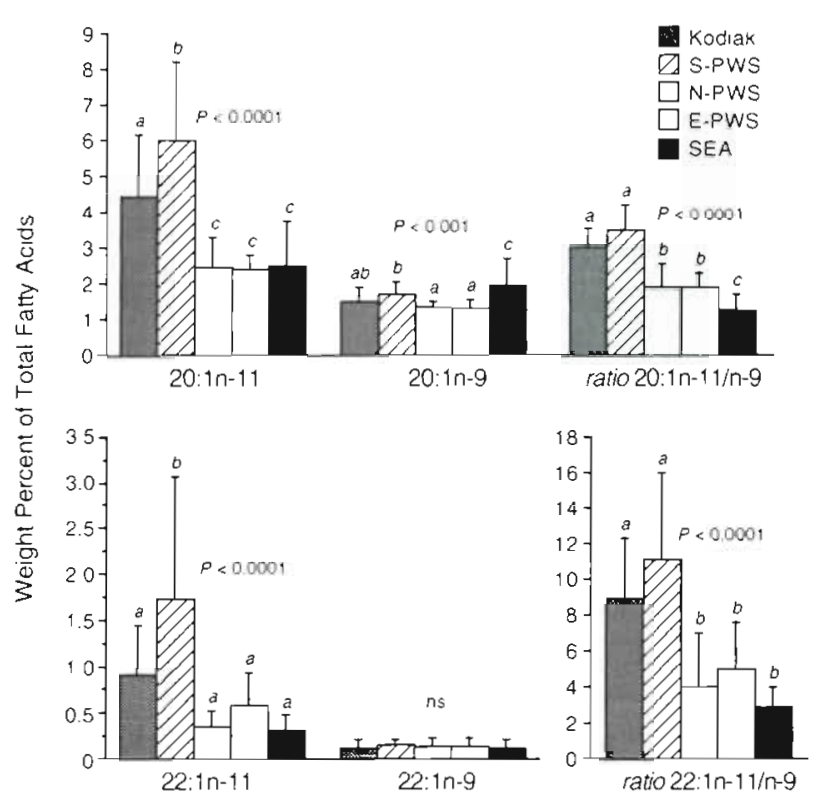

Fig. 2. Selected dietary fatty acids and important isomer ratios (mean + SD) in blubber of harbor seals sampled in Prince William Sound (southern, S-PWS, northern, N-PWS, and eastern, E-PWS) and the Gulf of Alaska (Kodiak and southeast Alaska, SEA) which can be used to distinguish groups by major geographical region in the Gulf of Alaska and within areas of PWS See Table 1 for sample sizes. Means (bars) with different letters above them were significantly different (ANOVA and Fisher's PLSD means separation test)

Kodiak seals were sent down the right side of the tree (Fig. 3). The total error rate for the tree was 8 out of 104 seals. All Kodiak and SEA animals, 62 of 63 southern PWS animals, and 12 of 19 northern PWS and eastern

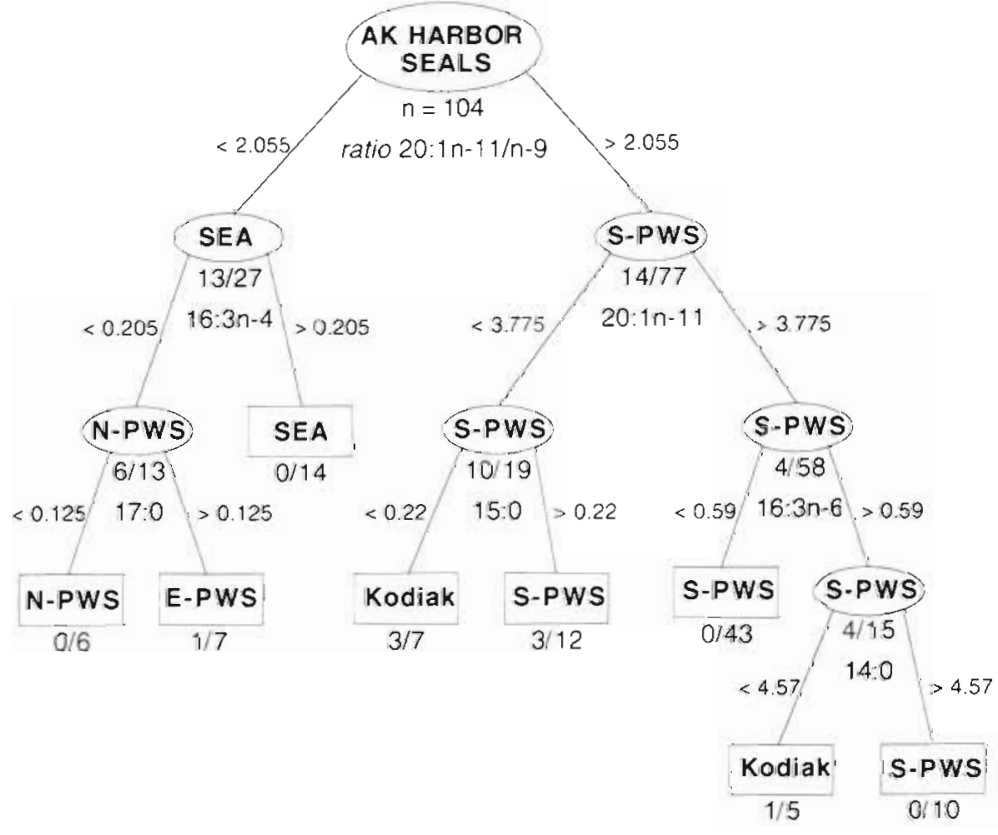

Fig. 3. Classification tree of all harbor seals sampled in PWS and the Gulf of Alaska (see Fig. 2 legend for abbreviations) using first algorithmically chosen variable at first node split (see Fig. 4). Ellupses represent intermediate nodes and rectangle boxes represent terminal nodes; labels within an ellipse or rectangle indicate the classification at that node as represented by the Iargest number of observations in that node. The fatty acid listed at each split is the variable chosen by the algorithm to create the split, with < and > values indicating the optimal splitting level (weight $\%$ ) of that fatty acid (see also Fig. 51. Fractions under each intermediate and terminal node indicate the number of misclassifications over the total number of observations in that mode. Total misclassification rate was $8 / 104$. Rate of seals correctly classified was $92 \%$ : S-PWS (62 of 63 ), N-PWS (6 of 9), E-PWS 6 of 10), Kodiak (8 of 8), and SE Alaska (14 of 14) 


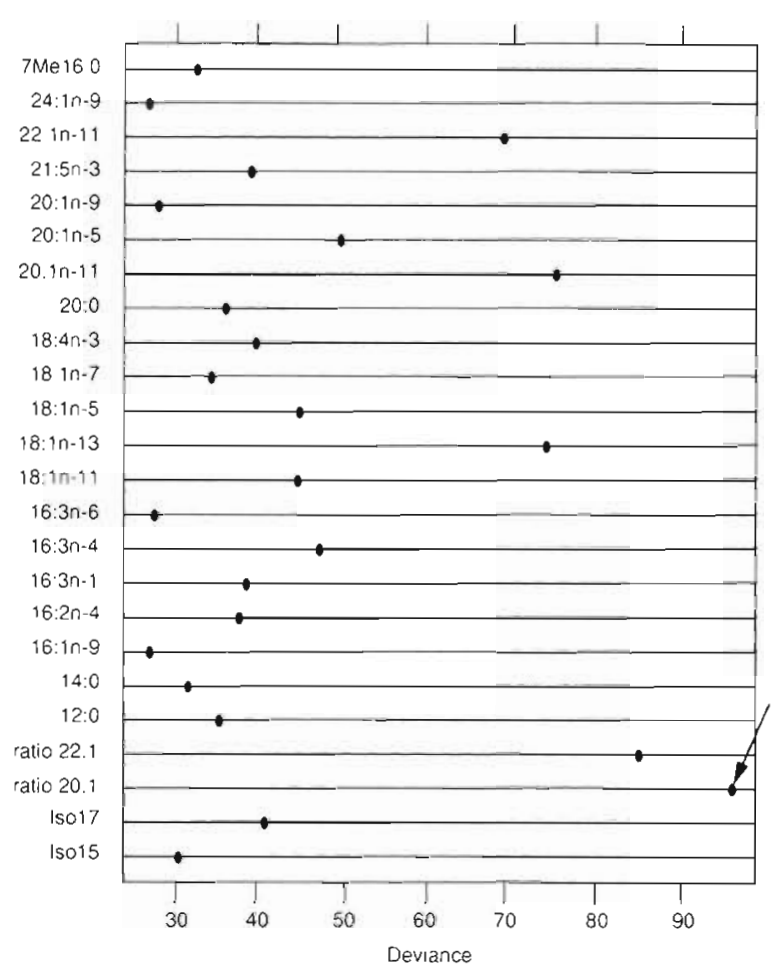

Fig. 4. Dot chart of the change in devlance for the optimal cutpoint for the top fatty acids considered for the first node. The ratio of $20: 1 n-11 / n-9$ had the largest change in deviance at $>90$ and thus was algorithmically chosen for the first node split (Fig. 3)
PWS animals were correctly classified to location by their fatty acid signatures. Box plots of the fatty acids selected by CART indicate splitting values and data points missclassified at each node for the tree (Fig. 5) and further demonstrate the differences between groups of seals.

The deviance plots (Fig. 4) indicated that other, and mostly abundant, fatty acids (e.g. ratio $22: 1 \mathrm{n}-11 / \mathrm{n}-9$, $22: 1 \mathrm{n}-11,18: 1 \mathrm{n}-13$, and 20:1n-11) could have been used as the initial splitting point. In fact, using the ratio of $22: 1 n-11 / n-9$ at the root node resulted in one less misclassification (7/104), despite the fact that its deviance was slightly lower. This alternate tree was similar to the original, but differed in that all E-PWS animals were correctly classified (10 of 10), but there was a slightly higher error rate for classifying northern PWS and Kodiak animals.

We compared the performance of the 2 initial classification trees (Fig. 3 and above) with that of linear discriminant analysis using for discriminant variables the 7 fatty acids chosen by CART in each of the above trees, the 18 most prevalent fatty acids by weight, or these 18 prevalent fatty acids in addition to the 2 ratios of 20:1 and 22:1 isomers. The linear discriminant functions based on the latter 2 sets of fatty acids had the lowest misclassification error rates of 6/104 and 4/104, respectively; the seals missclassified in these cases were a subset of those misclassified by CART. In con-
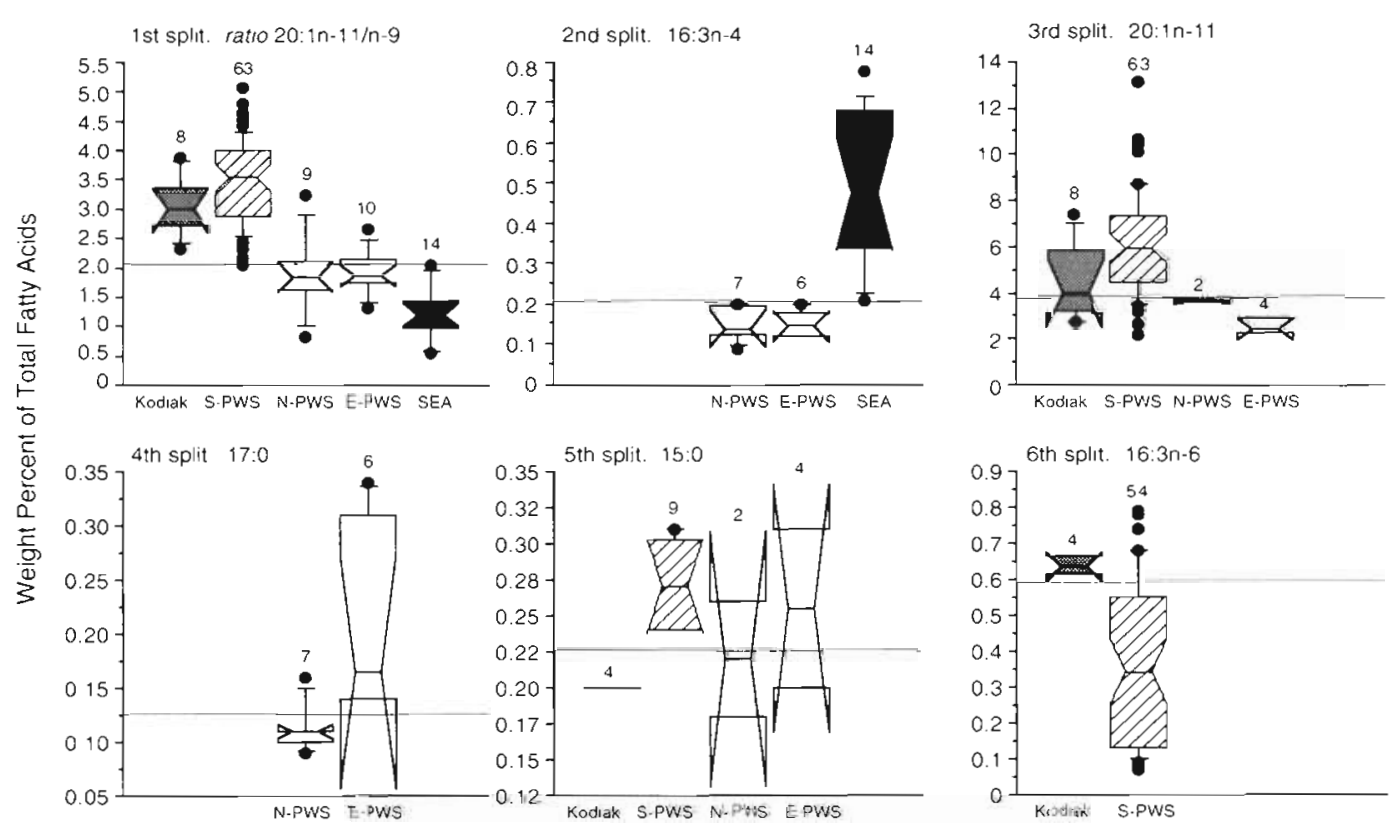

Fig. 5. Box plots of the algorithmically selected variables showing the distribution of the data at the first 6 nodes (see Fig. 3). The box plot for the root node variable contains data from all observations. The box plots for subsequent variables have removed the effects (observations) of the nodes higher up in the tree, i.e. once an observation has been classified, it is removed from any of the plots which follow, since it may mask the effects trying to be observed. The notched area of each box represents the $95 \%$ confidence interval on the mean; dots indicate outliers. The horizontal line represents the splitting value used by the CART algorithm. Number above each box represents number of observations contained within plot 
trast, the discriminant functions for the fatty acids chosen by the 2 CART trees (using only 7 fatty acids each) had higher misclassification rates of $14 / 104$ and $12 / 104$, respectively. Hence, as found previously (Smith et al. 1997), the results of both CART and discriminant analysis compared favorably with similar conclusions, although CART did not require an initial subjective selection of variables for analysis.

\section{Harbor seal fatty acids-Prince William Sound}

CART analysis also supported our findings (e.g. Fig. 2) that within PWS, blubber fatty acid composition of seals differed at the finer-scale of haulout location with a total of 6 out of 82 misclassifications (Fig. 6). Animals sampled in northern PWS could be accurately separated from those in eastern PWS, and within eastern PWS, there was an indication that the more northerly bay of Port Fidalgo (see Fig. 1) could be separated from the Port Gravina animals, but with some error All 63 southern PWS seals were correctly classified by their fatty acids (Fig. 6).

Lastly, within southern PWS, at an even finer-scale resolution in the area of Montague Island (Fig 1), there was evidence that seals sampled at Channel Island, Little Green Island, Stockdale Harbor, and Port Chalmers differed from one another in fatty acid composition, although this was associated with a somewhat higher misclassification rate (Fig. 7). Two of the 12 misclassifications were accounted for by the 2 Applegate Rock animals; if these were removed, the percent of animals correctly classified by fatty acid signature to their haulout site in the Montague area would be 51 of 61 or $84 \%$.

\section{Prey species fatty acids}

Morphometric and fat content data for prey species in PWS are summarized in Table 2 Data for herring and pollock were available over a range of sizes as well as seasons and locations within PWS. Herring had the highest average fat content of any species analyzed $(6.3 \% \pm 4.33 \mathrm{SD})$, but this ranged widely 10.6 to $19.1 \%$, primarily with season and also with location. In general, herring appeared to be lowest in fat in the spring and highest in fat by the fall. Pollock was relatively low and less variable in fat content at $1.7 \% \pm 0.92 \mathrm{SD}$. In both herring and pollock, length and mass were highly correlated ( $r \geq 0.91, p<0.0001$ ), but fat content was not correlated with either length or mass $(r \leq 0.33)$.

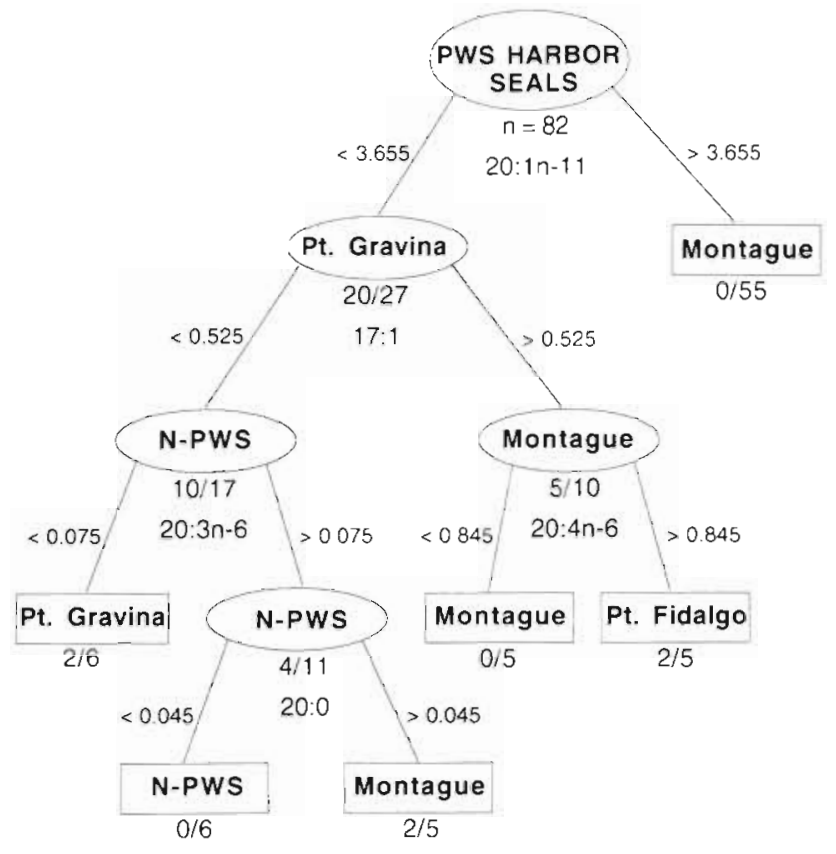

Fig. 6. Classification tree of harbor seals sampled only in PWS and grouped on a finer scale distribution of haulout sites. See Fig. 3 legend for explanation of tree. Total misclassification rate was $6 / 82$. Rate of seals correctly classified was $93 \%$ : Montague (63 of 63), N (6 of 9), Port Fidalgo ( 3 of 3), and Port Gravina ( 4 of 7 )

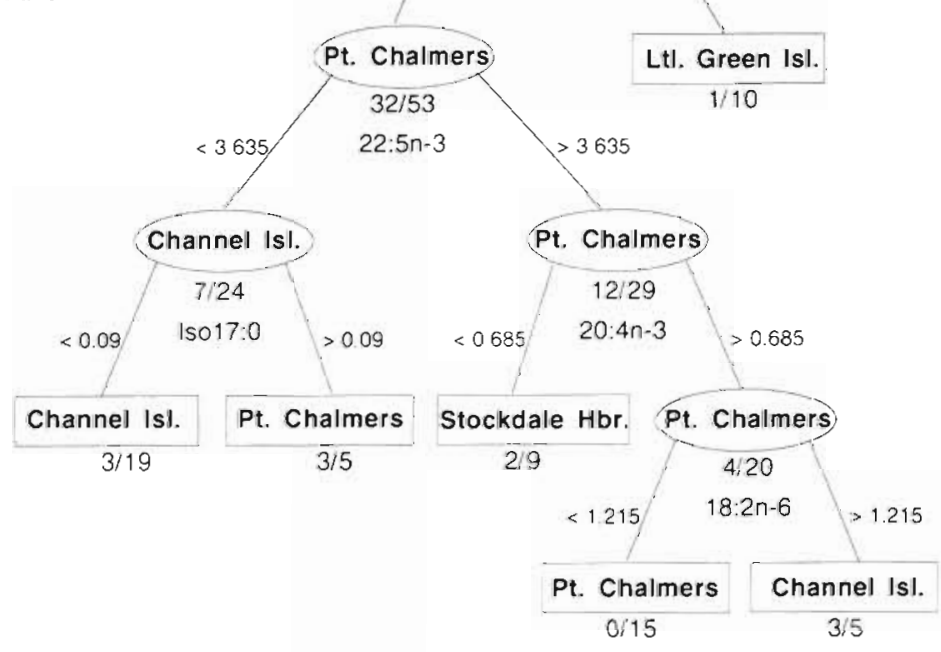

Fig. 7. Classification tree of harbor seals sampled only in the area of Montague Isl. in southern PWS and grouped on an again finer scale distribution of haulout sites. See Fig. 3 legend for explanation of tree. Total misclassification rate was $12 / 63$. Rate of seals correctly classified was $81 \%$ : Channel Isl. (18 of 20), Little Green Isl. (9 of 10), Port Chalmers (17 of 21), Stockdale Harbor (7 of 10), and Applegate Rocks (0 of 2) 
Table 2. Length, mass, and fat content of prey species collected in Prince William Sound $(\mathrm{n}=163)$. All values were derived from whole prey that were ground and analyzed individually. Only herring and pollock were available in sufticient numbers to be separated into 3 size classes

\begin{tabular}{|c|c|c|c|c|c|c|c|c|}
\hline \multirow{2}{*}{ Species } & \multirow{2}{*}{ Size class } & \multirow[t]{2}{*}{$\mathrm{n}$} & \multicolumn{2}{|c|}{ Length $(\mathrm{cm})$} & \multicolumn{2}{|c|}{$\operatorname{Mass}(\mathrm{g})$} & \multicolumn{2}{|c|}{ Fat content $(\%)$} \\
\hline & & & Mean $\pm S D$ & Range & Mean $\pm S D$ & Range & Mean $\pm \mathrm{SD}$ & Range \\
\hline \multirow[t]{3}{*}{ Herring } & Small & 19 & $9.9 \pm 1.4$ & $8.0-13.9$ & $8.1 \pm 4.4$ & $3.9-18.3$ & $3.0 \pm 1.2$ & $0.6-4.7$ \\
\hline & Medium & 28 & $18.7 \pm 0.9$ & $14.0-20.0$ & $69.6 \pm 17.1$ & $8.5-101.6$ & $8.7 \pm 5.0$ & $1.7-19.1$ \\
\hline & Large & 30 & $22.4 \pm 1.5$ & $20.1-28.0$ & $119.0 \pm 35.8$ & $62.7-208.0$ & $6.1 \pm 3.4$ & $1.1-13.2$ \\
\hline \multirow[t]{3}{*}{ Pollock } & Small & 17 & $10.4 \pm 0.5$ & $8.0-11.9$ & $6.7 \pm 1.0$ & $5.5-9.0$ & $1.5 \pm 1.1$ & $0.6-4.5$ \\
\hline & Medium & 8 & $14.7 \pm 0.9$ & $12.0-15.8$ & $25.8 \pm 6.3$ & $14.1-35.3$ & $2.6 \pm 0.8$ & $1.5-4.0$ \\
\hline & Large & 19 & $17.2 \pm 1.2$ & $15.9-20.0$ & $36.7 \pm 5.6$ & $29.4-49.3$ & $1.5 \pm 0.6$ & $0.8-2.9$ \\
\hline \multicolumn{2}{|c|}{ Pacific cod } & 10 & $19.3 \pm 1.1$ & $17.3-20.6$ & $57.5 \pm 20.0$ & $42.2-109.2$ & $2.3 \pm 0.8$ & $0.9-3.6$ \\
\hline \multicolumn{2}{|l|}{ Tomcod } & 5 & $20.0 \pm 5.2$ & $16.2-29.1$ & $77.9+77.0$ & $33.9-214.8$ & $1.1 \pm 0.3$ & $0.7-1.4$ \\
\hline \multicolumn{2}{|c|}{ Rainbow smelt } & 4 & $20.5 \pm 1.1$ & $19.6-21.5$ & $73.4 \pm 24.6$ & $52.1-108.4$ & $2.5 \pm 1.1$ & $1.8-4.1$ \\
\hline \multicolumn{2}{|c|}{ Rockfish } & 1 & 20.2 & & 173.9 & & 1.7 & \\
\hline \multicolumn{2}{|c|}{ Sandlance } & 9 & $10.9 \pm 0.5$ & $9.9-11.6$ & $9.1 \pm 1.4$ & $6.6-11.4$ & $1.2 \pm 0.5$ & $0.8-1.8$ \\
\hline \multicolumn{2}{|c|}{ Yellowfin sole } & 8 & $28.6 \pm 2.5$ & $25.6-33.1$ & $291.6 \pm 90.6$ & $188.1-436.8$ & $3.2 \pm 1.6$ & $1.5-5.3$ \\
\hline \multicolumn{2}{|l|}{ Octopus } & 2 & $36.5 \pm 5.0$ & $33.0-40.0$ & $303.2 \pm 151.0$ & $196.4-409.9$ & $1.3 \pm 0.3$ & $1.1-1.5$ \\
\hline \multicolumn{2}{|c|}{ Squid/shrimp mıx } & 3 & NA & & $31.1 \pm 11.4$ & $18.0-39.0$ & $1.6 \pm 1.3$ & $0.8-3.1$ \\
\hline
\end{tabular}

Table 3. Fatty acid composition of prey species collected in Prince William Sound $(\mathrm{n}=163)$. Values (excluding ratios) are mean weight percent \pm SD of fatty acids (32 out of 72 ) present at levels $\geq 0.5 \%$ in harbor seal blubber and/or prey species (see Table 1)

\begin{tabular}{|c|c|c|c|c|c|c|c|c|c|c|}
\hline & $\begin{array}{l}\text { Herring } \\
\mathrm{n}=77\end{array}$ & $\begin{array}{l}\text { Pollock } \\
n=44\end{array}$ & $\begin{array}{c}\text { Pacific } \\
\text { cod } \\
n=10\end{array}$ & $\begin{array}{c}\text { Tomcod } \\
n=5\end{array}$ & $\begin{array}{c}\text { Raınbow } \\
\text { smelt } \\
n=4\end{array}$ & $\begin{array}{c}\text { Rock- } \\
f_{1} \text { sh } \\
n=1\end{array}$ & $\begin{array}{l}\text { Sand- } \\
\text { lance } \\
n=9\end{array}$ & $\begin{array}{c}\text { Yellow- } \\
\text { fin sole } \\
\mathrm{n}=8\end{array}$ & $\begin{array}{c}\text { Octopus } \\
n=2\end{array}$ & $\begin{array}{c}\text { Squid/ } \\
\text { shrimp } \\
\mathrm{n}=3\end{array}$ \\
\hline $14: 0$ & $6.70 \pm 1.70$ & $3.52 \pm 1.26$ & $2.17 \pm 0.79$ & $1.23 \pm 0.41$ & $2.59 \pm 0.70$ & 3.44 & $3.23 \pm 1.13$ & $4.49 \pm 0.70$ & $1.94 \pm 0.33$ & $3.33 \pm 0.75$ \\
\hline $14: 1 n-5$ & $0.09 \pm 0.03$ & $0.06 \pm 0.03$ & $0.04 \pm 0.02$ & $0.02 \pm 0.01$ & $0.19 \pm 0.09$ & 0.08 & $0.04 \pm 0.02$ & $0.13 \pm 0.04$ & $0.09 \pm 0.01$ & $0.10 \pm 0.05$ \\
\hline $15: 0$ & $0.35 \pm 0.15$ & $0.26 \pm 0.05$ & $0.27 \pm 0.04$ & $0.61 \pm 0.21$ & $0.27 \pm 0.06$ & 0.31 & $047 \pm 0.10$ & $0.53 \pm 0.04$ & $0.28 \pm 0.02$ & $0.60 \pm 0.24$ \\
\hline Isol6 & $0.08 \pm 0.08$ & $0.14 \pm 0.14$ & $0.21 \pm 0.05$ & $0.21 \pm 0.09$ & $0.10 \pm 0.07$ & 0.19 & $0.22 \pm 0.10$ & $0.17 \pm 0.08$ & $0.68 \pm 0.05$ & $0.58 \pm 0.16$ \\
\hline $16: 0$ & $16.22 \pm 3.16$ & $14.55 \pm 2.77$ & $14.50 \pm 1.46$ & $14.82 \pm 0.84$ & $18.12 \pm 0.77$ & 17.22 & $19.15 \pm 0.85$ & $12.84 \pm 1.20$ & $14.87 \pm 1.09$ & $17.21 \pm 3.40$ \\
\hline $16: 1 n-11$ & $0.39 \pm 0.08$ & $0.35 \pm 0.05$ & $0.44 \pm 0.06$ & $0.71 \pm 0.15$ & $0.22 \pm 0.05$ & 0.45 & $0.42 \pm 0.03$ & $0.94 \pm 0.12$ & $0.45 \pm 0.01$ & $0.64 \pm 0.29$ \\
\hline $16: 1 n-9$ & $0.17 \pm 0.08$ & $0.18 \pm 0.06$ & $0.38 \pm 0.11$ & $0.43 \pm 0.03$ & $0.34 \pm 0.07$ & 0.25 & $0.30 \pm 0.04$ & $0.37 \pm 0.04$ & $0.26 \pm 0.00$ & $0.19 \pm 0.03$ \\
\hline $16: 1 \mathrm{n}-7$ & $5.29 \pm 1.41$ & $4.88 \pm 1.82$ & $3.84 \pm 0.70$ & $3.05 \pm 0.44$ & $10.47 \pm 3.30$ & 6.28 & $4.09 \pm 1.61$ & $6.43 \pm 1.24$ & $2.51 \pm 0.66$ & $4.96 \pm 0.36$ \\
\hline $16: 2 n-4$ & $0.29 \pm 0.15$ & $0.18 \pm 0.17$ & $0.47 \pm 0.13$ & $0.61 \pm 0.14$ & $0.28 \pm 0.21$ & 0.41 & $0.46 \pm 0.08$ & $0.77 \pm 0.10$ & $0.06 \pm 0.00$ & $0.09 \pm 0.02$ \\
\hline $16: 3 n-6$ & $0.45 \pm 0.23$ & $0.61 \pm 0.23$ & $0.19 \pm 0.10$ & $0.00 \pm 0.00$ & $0.23=0.28$ & 0.24 & $0.17 \pm 0.11$ & $0.30 \pm 0.06$ & $0.08 \pm 0.03$ & $0.50 \pm 0.28$ \\
\hline $17: 0$ & $0.17 \pm 0.09$ & $0.17 \pm 0.05$ & $0.22 \pm 0.07$ & $0.60 \pm 0.17$ & $0.23 \pm 0.08$ & 0.31 & $0.26 \pm 0.10$ & $0.31 \pm 0.06$ & $0.58 \pm 0.08$ & $0.39 \pm 0.20$ \\
\hline $17: 1$ & $0.24 \pm 0.11$ & $0.16 \pm 0.13$ & $0.31 \pm 0.11$ & $0.64 \pm 0.25$ & $0.30 \pm 0.09$ & 0.38 & $0.33 \pm 0.06$ & $0.43 \pm 0.07$ & $0.15 \pm 0.01$ & $0.85 \pm 0.34$ \\
\hline $16: 4 n-1$ & $0.53 \pm 0.32$ & $0.51 \pm 0.32$ & $0.16 \pm 0.18$ & $0.36 \pm 0.15$ & $0.13 \pm 0.06$ & 0.35 & $0.34 \pm 0.12$ & $0.20 \pm 0.08$ & $0.97 \pm 0.07$ & $0.56 \pm 0.12$ \\
\hline 18:0 & $1.99 \pm 0.71$ & $3.19 \pm 1.01$ & $3.85 \pm 0.51$ & $4.98 \pm 0.91$ & $3.80 \pm 0.42$ & 4.15 & $3.29 \pm 0.53$ & $2.75 \pm 0.56$ & $3.37 \pm 0.13$ & $2.50 \pm 0.37$ \\
\hline $18: 1 n-11$ & $0.44 \pm 0.24$ & $1.21 \pm 0.74$ & $1.09 \pm 0.45$ & $0.09 \pm 0.04$ & $010 \pm 0.04$ & 0.43 & $0.40 \pm 0.11$ & $0.62 \pm 0.14$ & $0.28 \pm 0.06$ & $0.18 \pm 0.06$ \\
\hline $18: 1 n-9$ & $12.34 \pm 3.95$ & $7.68 \pm 2.85$ & $15.51 \pm 2.25$ & $8.78 \pm 0.92$ & $18.42 \pm 5.26$ & 14.21 & $15.80 \pm 4.23$ & $11.25 \pm 1.71$ & $6.00 \pm 0.92$ & $10.80 \pm 0.18$ \\
\hline $18: 1 n-7$ & $2.60 \pm 0.82$ & $3.07 \pm 1.30$ & $4.03 \pm 0.55$ & $4.27 \pm 0.82$ & $4.76 \pm 0.23$ & 3.85 & $2.83 \pm 0.27$ & $3.63 \pm 0.45$ & $3.95 \pm 0.18$ & $5.61 \pm 0.10$ \\
\hline $18: 1 n-5$ & $0.52 \pm 0.10$ & $0.44 \pm 0.17$ & $0.43 \pm 0.07$ & $0.43 \pm 0.14$ & $0.46 \pm 0.08$ & 0.62 & $0.39 \pm 0.09$ & $0.56 \pm 0.11$ & $0.52 \pm 0.03$ & $0.42 \pm 0.15$ \\
\hline $18: 2 n-6$ & $0.89 \pm 0.21$ & $0.69 \pm 0.11$ & $0.70 \pm 0.16$ & $0.80 \pm 0.26$ & $0.54 \pm 0.36$ & 0.98 & $1.18 \pm 0.22$ & $0.94 \pm 0.08$ & $0.60 \pm 0.04$ & $0.78 \pm 0.02$ \\
\hline $18: 3 n-3$ & $0.72 \pm 0.35$ & $0.53 \pm 0.16$ & $0.44 \pm 0.17$ & $0.78 \pm 0.21$ & $0.30 \pm 0.27$ & 0.69 & $0.67 \pm 0.32$ & $0.59 \pm 0.10$ & $0.38 \pm 0.08$ & $0.62 \pm 0.04$ \\
\hline $18: 4 n-3$ & $1.53 \pm 0.76$ & $1.77 \pm 0.75$ & $0.56 \pm 0.31$ & $0.98 \pm 0.61$ & $0.25 \pm 0.10$ & 1.49 & $0.81 \pm 0.52$ & $0.94 \pm 0.19$ & $0.33 \pm 0.14$ & $0.76 \pm 0.51$ \\
\hline $20: 1 n-11$ & $7.12 \pm 5.38$ & $5.13 \pm 4.62$ & $2.53 \pm 1.00$ & $0.86 \pm 0.64$ & $0.40 \pm 0.16$ & 2.07 & $0.51 \pm 0.15$ & $7.17 \pm 2.15$ & $3.46 \pm 0.87$ & $1.62 \pm 0.64$ \\
\hline $20: 1 n-9$ & $2.81 \pm 1.37$ & $2.39 \pm 1.67$ & $2.10 \pm 0.67$ & $0.78 \pm 0.13$ & $0.62 \pm 0.28$ & 1.11 & $2.68 \pm 1.16$ & $1.94 \pm 0.29$ & $4.02 \pm 0.07$ & $1.38 \pm 0.13$ \\
\hline Ralio $20: 1^{\circ}$ & $2.61 \pm 1.99$ & $2.14 \pm 1.72$ & $1.22 \pm 0.39$ & $1.15 \pm 0.99$ & $0.84 \pm 0.66$ & 1.87 & $0.20 \pm 0.05$ & $3.64 \pm 0.71$ & $0.86 \pm 0.23$ & $1.21 \pm 0.57$ \\
\hline $20: 1 n-7$ & $0.26 \pm 0.09$ & $0.19 \pm 0.03$ & $0.52 \pm 0.28$ & $1.10 \pm 0.72$ & $0.25 \pm 0.30$ & 0.37 & $0.23 \pm 0.02$ & $1.47 \pm 0.28$ & $0.68 \pm 0.12$ & $0.93 \pm 0.51$ \\
\hline $20: 4 n-6$ & $0.52 \pm 0.25$ & $0.79 \pm 0.34$ & $2.14 \pm 0.55$ & $3.06 \pm 1.09$ & $1.74 \pm 0.93$ & 1.80 & $1.02 \pm 0.23$ & $2.15 \pm 0.55$ & $4.24 \pm 1.16$ & $1.92 \pm 0.95$ \\
\hline $20: 4 n-3$ & $0.47 \pm 0.15$ & $0.57 \pm 0.12$ & $0.61 \pm 0.15$ & $0.54 \pm 0.16$ & $0.20 \pm 0.02$ & 0.49 & $0.46 \pm 0.10$ & $0.46 \pm 0.06$ & $0.24 \pm 0.04$ & $0.30 \pm 0.04$ \\
\hline $20: 5 n-3$ & $8.74 \pm 2.40$ & $12.80 \pm 2.43$ & $11.84 \pm 2.18$ & $13.63 \pm 1.12$ & $8.80 \pm 1.07$ & 9.38 & $9.54 \pm 1.09$ & $9.21 \pm 1.13$ & $16.37 \pm 0.11$ & $17.74 \pm 0.85$ \\
\hline $22: 1 n-11$ & $9.29 \pm 6.19$ & $5.57 \pm 4.94$ & $1.38 \pm 0.67$ & $0.13 \pm 0.03$ & $0.15 \pm 0.02$ & 1.50 & $2.37 \pm 1.16$ & $4.05 \pm 1.51$ & $2.97 \pm 0.73$ & $1.62 \pm 0.65$ \\
\hline $22: 1 n-9$ & $0.48 \pm 0.15$ & $0.53 \pm 0.24$ & $0.30 \pm 0.07$ & $0.15 \pm 0.03$ & $0.14 \pm 0.06$ & 0.24 & $0.38 \pm 0.09$ & $0.43 \pm 0.08$ & $1.06 \pm 0.27$ & $0.55 \pm 0.19$ \\
\hline Ratio22:1 & $18.08 \pm 10.85$ & $9.38+7.46$ & $4.69 \pm 2.06$ & $0.96 \pm 0.40$ & $1.19 \pm 0.36$ & 6.23 & $6.05 \pm 2.20$ & $9.28 \pm 2.44$ & $2.80 \pm 0.02$ & $2.88 \pm 0.47$ \\
\hline $22 \cdot 5 n-3$ & $0.88 \pm 0.26$ & $1.23 \pm 0.22$ & $2.69 \pm 0.66$ & $3.80 \pm 1.48$ & $1.47 \pm 0.42$ & 1.33 & $1.08 \pm 0.07$ & $3.03 \pm 0.46$ & $1.57 \pm 0.21$ & $1.09 \pm 0.50$ \\
\hline $22: 6 n-3$ & $12.93 \pm 6.06$ & $21.06 \pm 6.29$ & $21.16 \pm 2.07$ & $24.50 \pm 4.07$ & $20.22 \pm 5.30$ & 20.01 & $21.58 \pm 6.47$ & $14.78 \pm 2.30$ & $21.91 \pm 1.90$ & $15.40 \pm 0.28$ \\
\hline $24: 1 n-9$ & $0.78 \pm 0.26$ & $0.97 \pm 0.39$ & $0.82 \pm 0.14$ & $0.60 \pm 0.33$ & $0.86 \pm 0.21$ & 0.78 & $1.48 \pm 0.28$ & $0.64 \pm 0.09$ & $0.34 \pm 0.04$ & $0.50 \pm 0.17$ \\
\hline
\end{tabular}


The same approximately 70 fatty acids and isomers found in harbor seal blubber were routinely identified in PWS prey (Table 3). Differences between prey species in many components were apparent and are illustrated by several of the important indicator fatty acids and their ratios (Fig 8). For instance, the levels of $20: 1 \mathrm{n}-11$ and its ratio with the $\mathrm{n}-9$ isomer were particularly high in herring, followed by yellowfin sole and pollock. Species such as sandlance were distinguished by being notably low in $20: 1 n-11$, but quite high in $20: 1 n-9$, resulting in a very low $n-11 / n-9$ ratio. Levels of these 2 components were nearly equal to one another in Pacific cod, tomcod, and octopus, but absolute values differed greatly between species. Levels of $22: 1 n-11$, and its ratio with $22: 1 n-9$, were equally variable among species and highest in herring, pollock, yellowfin sole, and sandlance (Fig. 8).

Comparing all 70 fatty acids across species of prey is best accomplished using CART analysis. The dot plot of deviances (a plot similar to Fig. 4) indicated several appropriate choices for the variable at the root node split. However, the ratio of $22: 1 n-11 / 22: 1 n-9$ resulted in the best classification tree ( 3 out of 157 misclassifications) for identifying prey species by fatty acid signature (Fig. 9). Although pollock and herring were each variable in fatty acid composition and appeared

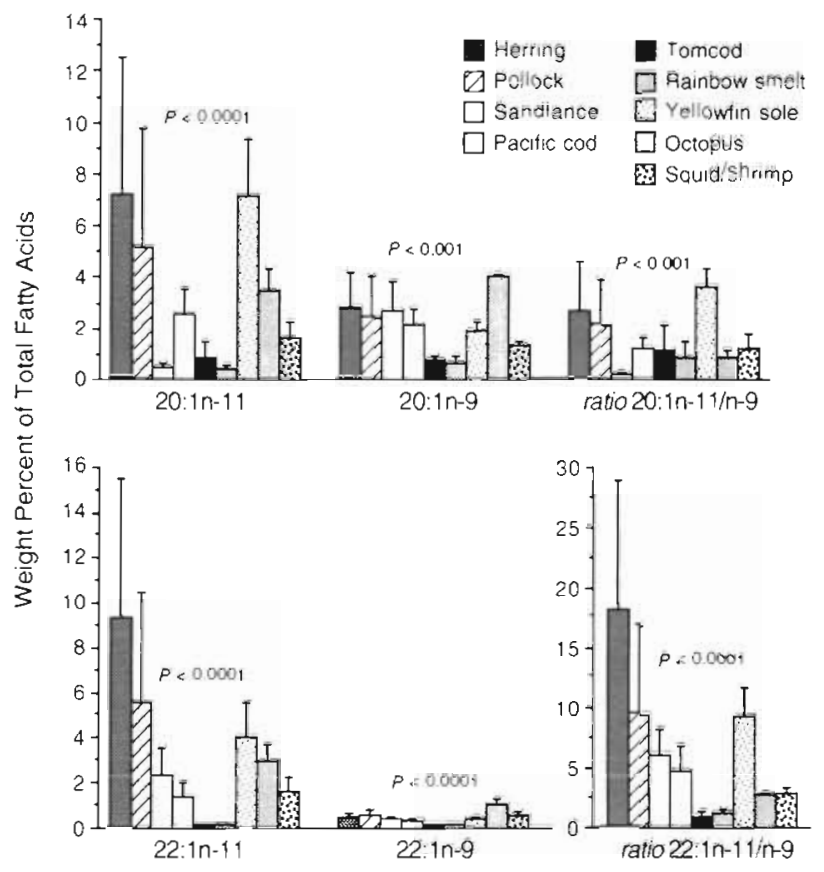

Fig. 8. Selected fatty acids and important isomer ratios (mean + SD) in prey species collected in PWS. See Table 3 for sample sizes. Significant differences were found for components between most species (ANOVA), but superscripts are not presented

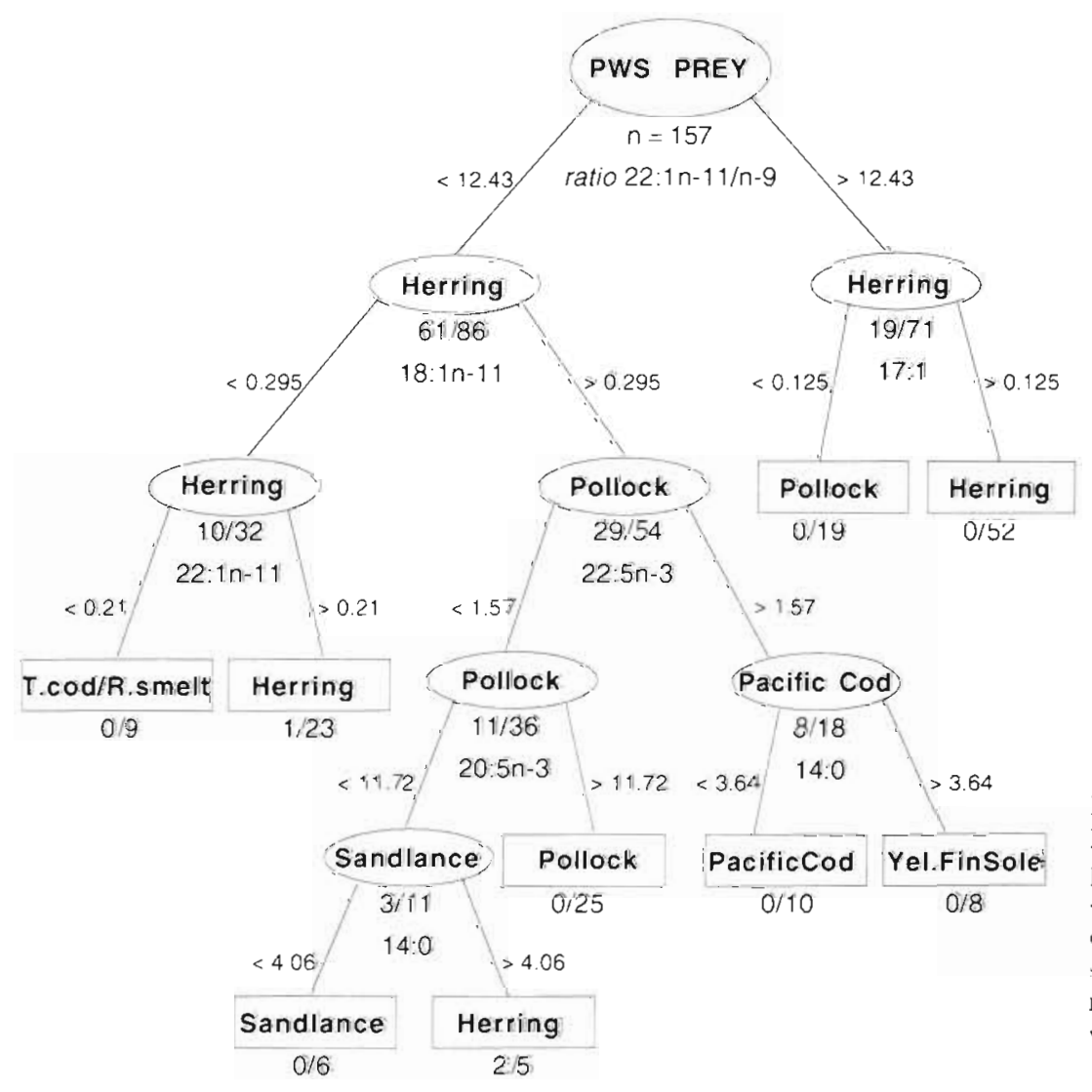

Fig. 9. Classification tree of prey collected in PWS across species. See Fig. 3 legend for explanation of tree. Species with sample sizes $<4$ (rockfish, octopus, squid/shrimp) were excluded from CART analysis. Total misclassification rate was $3 / 157$. Rate of prey correctly classified by their fatty acid signatures was $98 \%$ : all species were correctly classified $(100 \%)$, except sandlance at 6 of 9 
in nodes on both sides of the tree, no herring or pollock were missclassified 10 out of 77 and 0 out of 44, respectively) All Pacific cod and yellowfin sole were separated and correctly classified (Fig. 9). Tomcod ( $n=5$ ) and rainbow smelt ( $n=4)$ traveled together, which is not surprising given their similarities (Fig. 8) and small sample sizes. Sample sizes of 4 were the smallest that could be included in CART analysis; hence octopus, squid/shrimp, and rockfish could not be analyzed

Again, we compared the performance of the initial prey classification tree (Fig. 9) with that of linear discrimminant analysis using the 8 fatty acids chosen by CART (Fig. 9), the 18 most prevalent fatty acids by weight, or these in addition to the isomer ratios of $20: 1$ and $22: 1$. The latter 2 discriminant functions had similar misclassification rates (4/157) to that of the CART tree $(3 / 157)$, whereas the former discriminant function using only the 8 fatty acids chosen by CART had a higher misclassification rate of $10 / 157$.

The CART tree (Fig 9) clearly identified prey species, but the appearance of herring and pollock on both sides of the tree pointed to their variability in fatty acid composition. For these species sample sizes were large enough that variability caused by factors such as location or size could be examined. Selecting 6 important indicators and ratios and plotting levels of these as a function of body length showed a major effect of size on fatty acid signature within each species (Figs. 10 \& 11). In both species, $20: 1 n-11$, the ratio of $20: 1 n-11 / n-9,22: 1 n-11$, and the ratio of $22: 1 n-11 / n-9$ increased directly with increasing body length, while 20:5n-3 and $22: 6 n-3$ decreased with increasing length (although 22:6n-3 was not significant for pollock, Fig 11). In general, 50 to $70 \%$ of the variation in levels of these components within species was explained by their body length and the relationships existed both within and across locations in PWS. Regressing these fatty acid levels against body mass resulted in similar but slightly less significant relation-
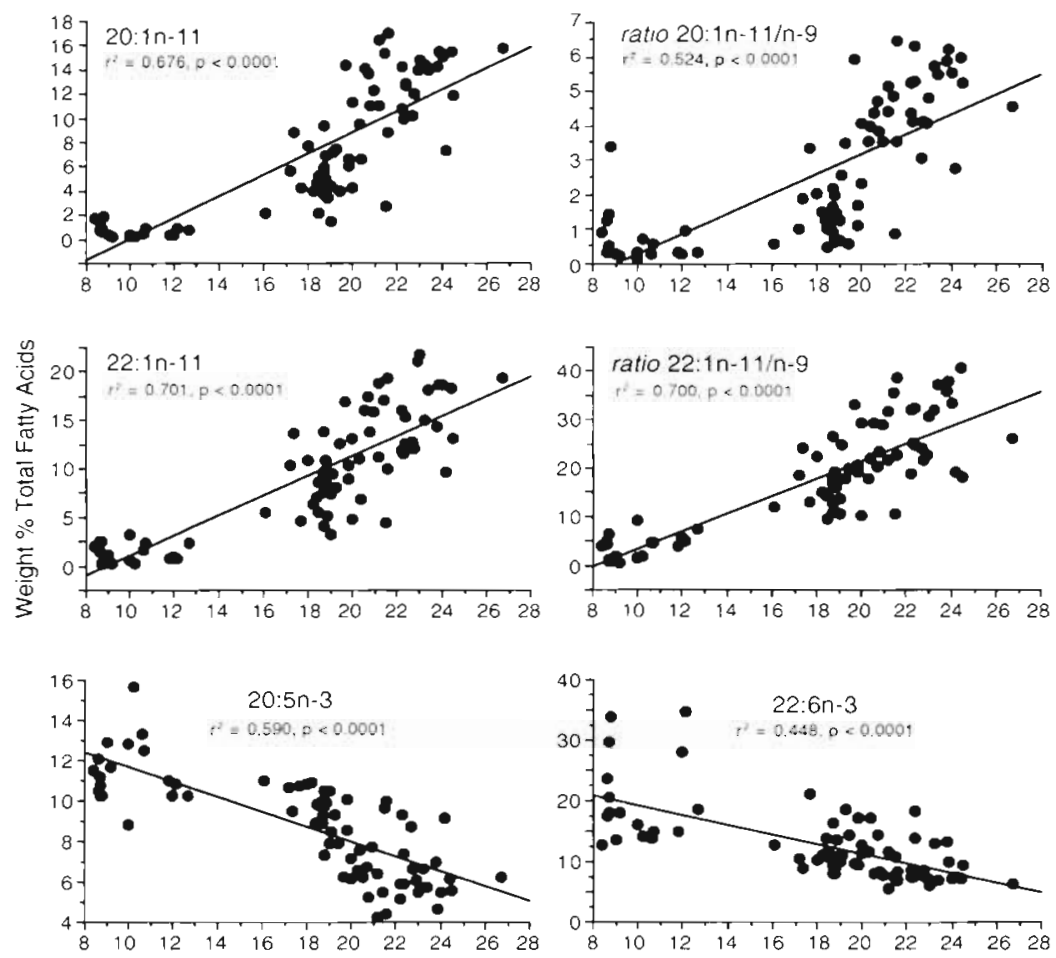

Length $(\mathrm{cm})$

Fig. 10. Variation in selected fatty acids and important isomers in herring $(\mathrm{n}=77$ ) from PWS as a function of body length
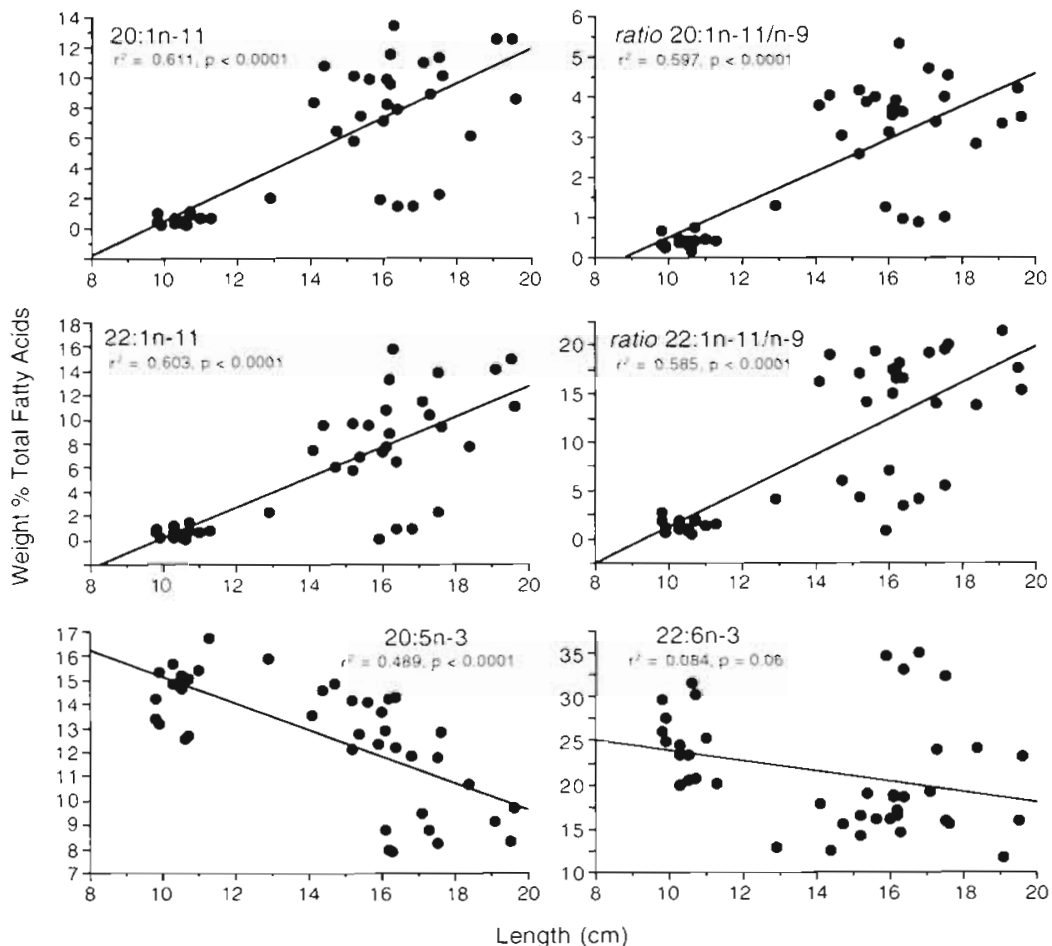

Fig. 11 Variation in selected fatty acids and important isomers in pollock $(\mathrm{n}=44)$ from PWS as a function of body length 
ships. However, there was no relationship between differing levels of specific fatty acids and fat content in either species $\left(\mathrm{r}^{2}<0.05\right)$.

We created size classes for herring and pollock, by dividing the length distribution of our samples by 3 , and incorporated those classes into the CART analysis (Fig. 12). This produced a tree that again separated species, but demonstrated why herring and pollock had occurred on both sides of the initial (Fig. 9) prey tree. Although a different root node variable was chosen (ratio of $20: 1 n-11 / n-9$ ) and there was a somewhat higher error rate overall (16 out of 157 misclassifications), small herring and small pollock moved initially together down the left node, but eventually separated from one another. Similarly, medium- and large-sized herring and pollock moved together initially, primarily down the right side of the tree, and later separated (Fig, 12). Most of the other species continued to be classified by their fatty acid signature

Herring and pollock fatty acid signatures also differed by collection area within PWS (see Fig. 1). To avoid one large and cumbersome tree, we grew separate trees for herring and pollock, incorporating both

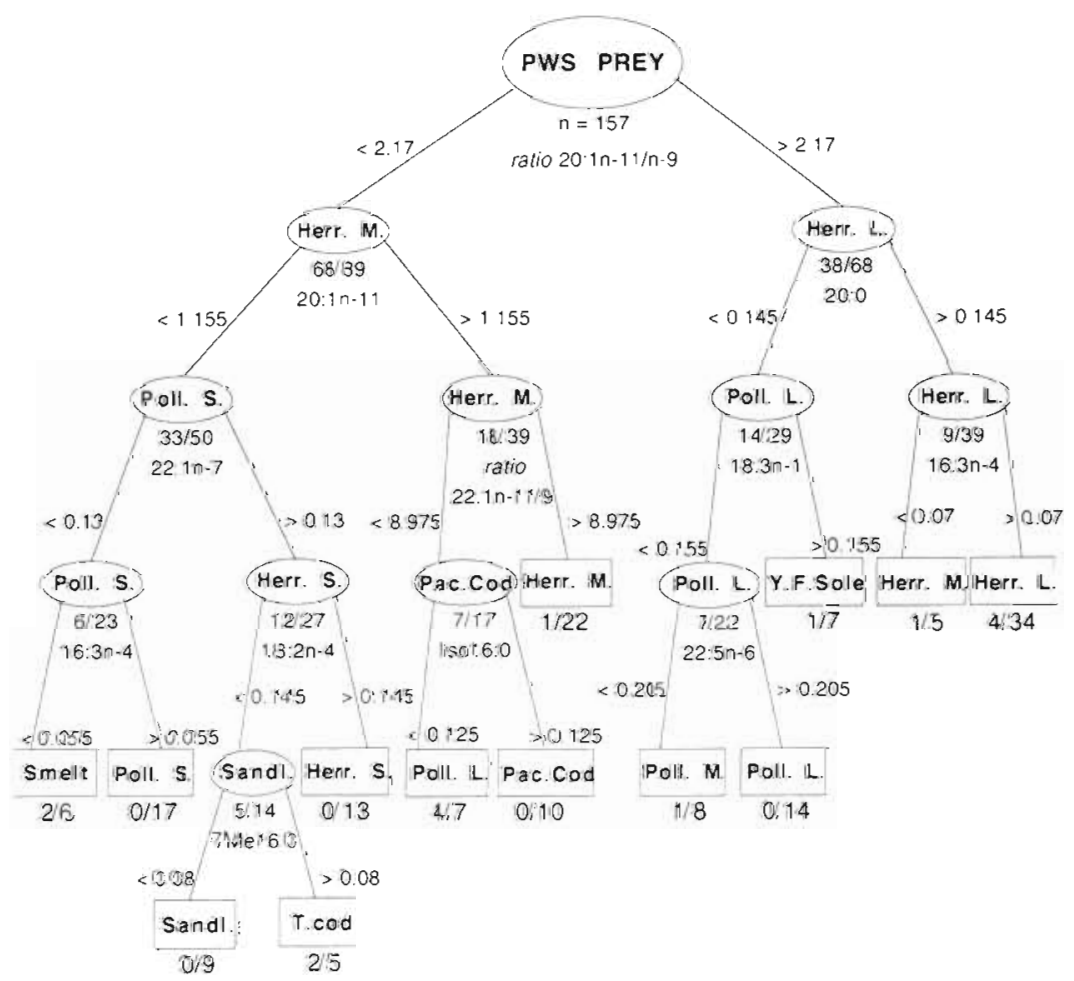

Fig. 12. Classification tree of prey collected in PWS across species, but including divisions of 3 size classes within herring and within pollock (see Table 2). See Fig. 3 legend for explanation of tree. Species with sample sizes < 4 (rockfish, octopus, squid/shrimp) were excluded from CART analysis. Total misclassification rate was $16 / 157$. Rate of prey correctly classified by their fatty acid signatures was $90 \%$ : herring $S(13$ of 19$)$, M (25 of 28), L (30 of 30), pollock S (17 of 17$)$, M (7 of 8), L (17 of 19), Pacific cod (10 of 10), tomcod (3 of 5), rambow smelt (4 of 4) sandlance (9 of 9 ) and yellowfin sole ( 6 of 8 ) size class and collection location in the CART analysis. Herring could be identified by size-class and location within PWS with a total of 7 out of 77 misclassifications, again with small and large individuals appearing on opposite sides of the tree (Fig. 13). Similarly, pollock could be identified by size-class and location within PWS with a total of 2 out of 41 misclassifications (Fig. 14).

\section{DISCUSSION}

Prince William Sound is a large, complex estuarine system that also has characteristics of a small inland sea (Niebauer et al. 1994). Localized habitats have differing depths (up to $700 \mathrm{~m}$ ), temperatures, and salinities, and levels and patterns of glacial, fresh and saltwater input (Walters et al. 1988, Niebauer et al 994) which are likely to result in different food web (e.g. Lalli \& Parsons 1993). Since tatty acid signatures are significantly affected by spatial or temporal heterogeneity in habitats and food webs (Sargent et al. 1988, Iverson 1993, St. John \& Lund 1996), analyses of fatty acids in harbor seals and their prey should provide an opportunity to study the spatial scales of foraging and habitat use. Our findings support the notion of differences in habitat use and foraging on small spatial scales in both harbor seals and their prey in PWS, and at larger spatial scales elsewhere in the Gulf of Alaska.

Prey species in PWS differed notably in fatty acid composition and could be readily separated from one another using CART (Figs. 8 \& 9). Additionally, not only could herring and pollock be differentiated from one another using fatty acid signatures, but they could also be distinguished by size-class and location within PWS (Figs. 12 to 14). The finding that the fatty acid composition of herring and pollock was directly related to body size (Figs. 10 \& 11) indicates that the diets of these fish change with size and age. Indeed, fish such as pollock begin life feeding on small zooplankton, copepods eggs and nauplii, followed by larger zooplankton, and finally becoming piscivores as adults (Pereyra et al. 1976, Frost \& Lowry 1981, Lalli \& Parsons 1993). Herring are thought to occupy lower trophic levels feeding mainly on zooplankton, but including small fishes as 


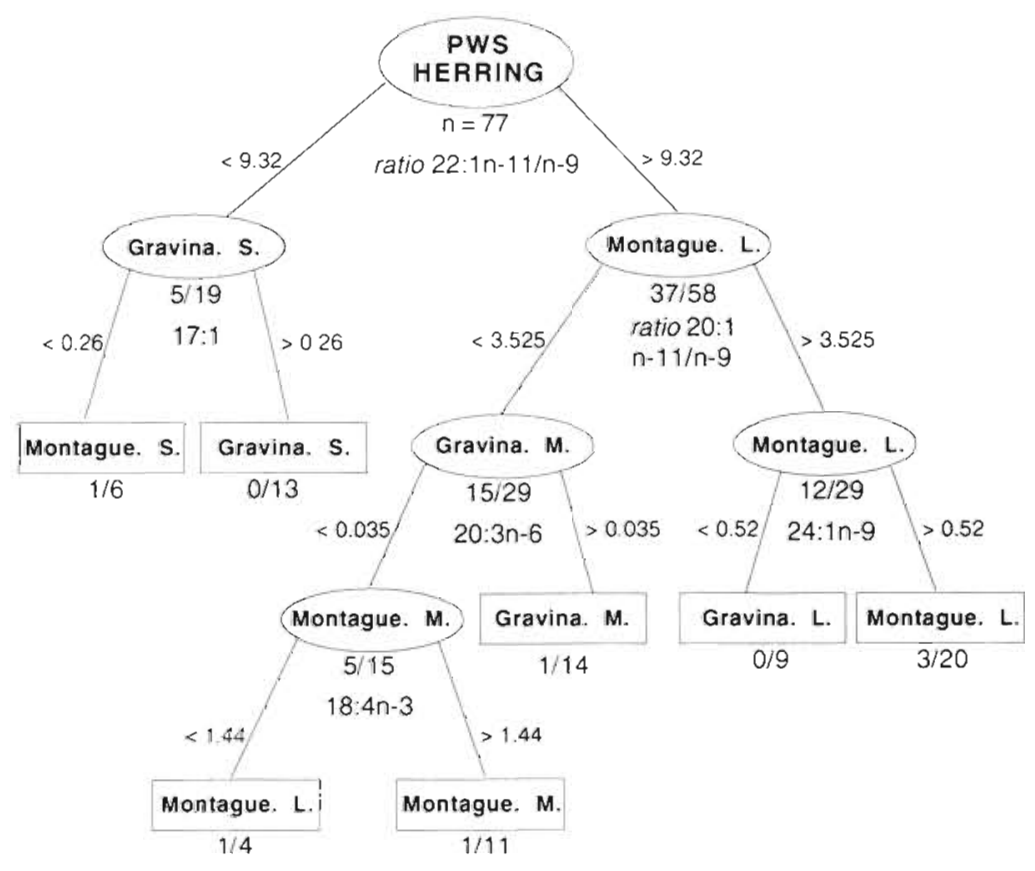

Fig. 13. Classification tree of herring across divisions of 3 size classes (see Table 2) and grouped by a finer scale distribution within PWS. See Fig. 3 legend for explanation of tree. Total misclassification rate was 7/77. Rate of herring correctly classified to location and size by their fatty acid signatures was $91 \%$ : Montague S (5 of 5), Pt. Gravina S (13 of 14), Montague M (10 of 12), Pt. Gravina M (13 of 16), Montague L (20 of 20), and Pt. Gravina L (9 of 10 ) pollock, one could essentially determine its size-class and location within the study area with reasonable certainty (e.g. Figs. 12 to 14 ). This could provide an important tool for studying foraging ecology and stock structure of fish species. Also, these prey characteristics should enhance the power of using fatty acids for examining foraging and feeding behavior in predators such as harbor seals within PWS, since they should result in different blubber fatty acid patterns of seals feeding in one area versus another.

The same variety of fatty acids and isomers were found in Alaska harbor seal blubber as in PWS prey species. All seals had high levels of 20:1n-11, particularly in relation to its $n-9$ isomer. In contrast, in phocid seals on the Atlantic coast (harbor seals, grey seals Halichoerus grypus, harp seals and hooded seals Cystophora cristata), $20: 1 \mathrm{n}-9$ is always the major isomer and $20: 1 n-11$ is minor and often unmeasurable (Iverson 1988, Iverson et al. 1995, Kirsch et al. 1995). This is a direct result of the composition of most Atlantic prey species,

they get older (NRC 1996). Differences in fatty acid signatures in herring and pollock within size classes also suggested localized habitat and feeding differences of these species within areas of PWS. These conclusions about size/age and geographic differences in herring and pollock diets based on fatty acid analysis are supported by the results of extensive stomach content analysis of these species in PWS. Sturdevant (1996) found substantial differences in the diets of pollock and herring from northern and southern PWS, and between small and large fish. Sturdevant (1996) also found that the diet of small pollock was more like that of small herring than large herring, and that diets of larger pollock were more similar to that of large herring. Although our data among seasons are currently limited, the fatty acid composition of herring and pollock was not related to their relative fatness. If indeed herring reduce or cease feeding in the winter (e.g. Sturdevant 1996), this may support the notion that, even during poor feeding conditions, the original food web signature is retained in the existing lipid stores of the prey (Martin et al. 1984, St. John \& Lund 1996).

One result of these findings is that given a fatty acid composition of an unknown herring or including herring, pollock, sandlance, capelin, and cod (Iverson 1993, Kirsch et al. 1995, S. J. Iverson, W. D. Bowen \& R. G. Ackman unpubl. data). Hence, the finding of high levels of 20:1n-11 and its ratio in PWS seals

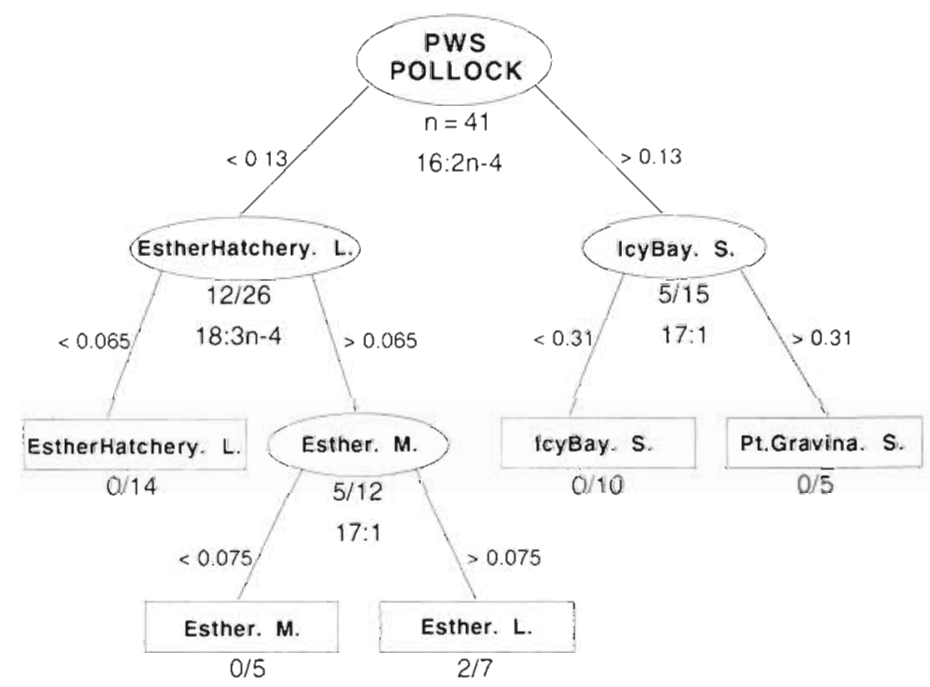

Fig. 14. Classification tree of pollock across divisions of 3 size classes (see Table 2) and grouped by a finer scale distribution within PWS. See Fig. 3 legend for explanation of tree. Total misclassification rate was $2 / 41$ Rate of pollock correctly classified to location and size by their fatty acid signatures was $95 \%$ : all pollock were correctly classified $(100 \%)$, except Esther Isl. M (5 of 7$)$ 
reflects the prey base and indicates that PWS prey differs markedly in fatty acid composition from comparable species in the Atlantic. Indeed, the fatty acid composition of prey in PWS explained the occurrence of reversed ratios of the 20:1 isomers in Alaska seals (Table 3, Fig. 8), which provides further validation for fatty acids reflecting diet. Additionally, the component $22: 1 n-11$ and its ratio to $n-9$, which are useful dietary indicators on the Atlantic coast originating from various copepods (e.g. Iverson 1993), were also useful indicators in Alaska prey species. These fatty acids and ratios were often chosen by CART to begin separation of seals, as well as prey by species (e.g. Figs. 3, 9 \& 12).

Within PWS over a spatial scale of about $80 \mathrm{~km}$, the large differences observed in fatty acid patterns between harbor seals sampled in the southern part versus in other areas (Figs. 3 to 6) indicate that these groups had different diets. Seals differed in fatty acid signatures, and hence likely feeding habits, even within small areas, such as Port Fidalgo and Port Gravina (see Fig 1) separated by about $25 \mathrm{~km}$ in eastern PWS (Fig. 6), or over a finer scale of 9 to $15 \mathrm{~km}$ in various bays and islands around Montague Island (Fig. 7). Our results suggest that seals sampled at a particular haulout location had foraged and fed nearby or at least on the same general prey sources. Misclassifications in the CART trees could represent those seals which were simply more wide-ranging in their foraging patterns or that had highly individual feeding habits. These conclusions are supported by data on movements of satellite-tagged seals. Of 30 harbor seals tagged in PWS between 1992 and 1995, only 5 left PWS for any time, and most remained close to the specific location at which they were tagged throughout the study period (Frost et al. 1995, 1996). Overall, findings from fatty acid signature analysis and satellite telemetry suggest that harbor seals in PWS may depend on a very localized prey base.

Although only a limited number of samples were available from other parts of Alaska, fatty acid signature analysis also indicated differences in feeding on a broader geographical scale of 400 to $800 \mathrm{~km}$. Seals from SEA were easily distinguished from PWS and Kodiak animals. Kodiak seals shared some characteristics with those from southern PWS, and some difficulty in separating them probably results from a more common diet.

Data on fatty acids in the prey base of harbor seals in PWS are currently incomplete, which limits our ability to identify the specific composition of their diet. However, as a preliminary step in identifying prey being consumed, we can compare some important components in harbor seals and their potential prey based on ratios of associated isomers. For instance, high levels of the ratio of $20: 1 n-11 / n-9$ found in seals from Kodiak
Island (3.04) and southern PWS (3.48) were only found at comparable levels in large herring (4.61), large and medium pollock (3.24 and 3.35, respectively), and yellowfin sole (3.64). Lower values for this ratio were present in northern and eastern PWS (1.85 to 1.93) and SEA (1.23) seals, and corresponded more closely with values for the other prey species $(0.20$ to 1.87 ), as well as small and medium herring $(0.71$ and 1.75 , respectively) and small pollock (0.35) (Tables 1 \& 3). Furthermore, if the data from individual seals were applied to the classification rules derived from the most comprehensive prey tree (Fig. 12), there would be 2 initial allocations of seals to 'diets' (Table 4) These results suggest that a large portion of the diet of southern PWS seals might be comprised of the larger herring (20 to $28 \mathrm{~cm}$ ) and pollock (12 to $20 \mathrm{~cm})$, as well as flatfish such as yellowfin sole. In contrast, the seals sampled in northern and eastern PWS were grouped with and thus would appear to feed more on items such as small to medium sized herring $(8$ to $20 \mathrm{~cm})$ and small pollock ( 8 to $12 \mathrm{~cm}$ ), or perhaps on other prey items such as sandlance, cod, octopus, squid, and shrimp (Table 4). Like southern PWS seals, those from Kodiak appeared to be feeding on the larger size classes of pollock and herring, while seals from SEA appeared to have a diet more like the northern and eastern PWS seals. The fatty acid composition of the prey base in SEA may dif-

Table 4. Proportion of seals and prey which would be grouped by the 2 major prey-tree nodes using the splitting variable: ratio 20:1n-11/n-9, based upon PWS prey tree with size classes (Fig. 12). Values are percent of each species and/or group analyzed

\begin{tabular}{|c|c|c|c|c|}
\hline & & n & $\begin{array}{c}\text { Left node } \\
\%\end{array}$ & $\begin{array}{c}\text { Right node } \\
\%\end{array}$ \\
\hline \multicolumn{5}{|l|}{ Seals } \\
\hline \multicolumn{2}{|l|}{ S-PWS } & 63 & 2 & 98 \\
\hline \multicolumn{2}{|l|}{ N-PWS } & 9 & 78 & 22 \\
\hline \multicolumn{2}{|l|}{ E-PWS } & 10 & 80 & 20 \\
\hline \multicolumn{2}{|l|}{ Kodiak } & 8 & & 100 \\
\hline \multicolumn{2}{|l|}{ SEA } & 14 & 100 & \\
\hline \multicolumn{5}{|l|}{ Prey } \\
\hline \multirow[t]{3}{*}{ Herrıng } & Small & 19 & 95 & 5 \\
\hline & Medium & 28 & 75 & 25 \\
\hline & Large & 30 & 3 & 97 \\
\hline \multirow[t]{3}{*}{ Pollock } & Small & 17 & 100 & \\
\hline & Medium & 8 & 12 & 88 \\
\hline & Large & 19 & 21 & 79 \\
\hline \multicolumn{2}{|c|}{ Pacific cod } & 10 & 100 & \\
\hline \multicolumn{2}{|l|}{ Tomcod } & 5 & 80 & 20 \\
\hline \multicolumn{2}{|c|}{ Rainbow smelt } & 4 & 100 & \\
\hline \multicolumn{2}{|c|}{ Rockfish } & 1 & 100 & \\
\hline \multicolumn{2}{|c|}{ Sandiance } & 9 & 100 & \\
\hline \multicolumn{2}{|c|}{ Yellowfin sole } & 8 & & 100 \\
\hline \multicolumn{2}{|l|}{ Octopus } & 2 & 100 & \\
\hline \multicolumn{2}{|c|}{ Squid/shramp mix } & 3 & 100 & \\
\hline
\end{tabular}


fer considerably from PWS, so conclusions about diets of those seals are very tentative. Similar patterns with seals and prey species were found for the other ratio $(22: 1 n-11 / n-9)$, as well as other indicator components Clearly, a more comprehensive data base on the fatty acid composition of all potential prey species is required for further elucidation of foraging patterns of harbor seals in PWS and elsewhere in Alaska. Additionally, conclusions drawn from single-point comparisons of individual fatty acids are limited, since predator signatures will never exactly match that of their prey. Thus, further development of analytical techniques, such as development of a comprehensive pattern-matching program, mathematically comparing all complete signatures, combined with a maximum likelihood estimation, is also needed.

Past studies of harbor seal diets in the Gulf of Alaska and elsewhere have mostly used stomach content and fecal analyses (Pitcher 1980a, b, Frost \& Lowry 1986, Payne \& Selzer 1989, Bowen \& Harrison 1996, Tollit \& Thompson 1996). Unfortunately, such studies give biased results due to different rates of passage of food from the gut, differences in ingestion and digestion of hard parts (e.g. complete digestion of fragile otoliths from small fish such as herring), and long-term retention of items such as cephalopod beaks (Pitcher 1980b, Bigg \& Fawcett 1985, Pierce \& Boyle 1991). Despite these potential limitations, stomach content data have indicated that the top-ranked prey species in harbor seal diets in Alaska from 1973 to 1978 were pollock and octopus, followed by capelin, euchalon, and herring (Pitcher 1980a, b). Those data also suggested that the diets of harbor seals in PWS contained higher proportions of pollock and herring, while diets of seals from Kodiak contained more flatfish, capelin and octopus. Because of differences in timing and in methods we cannot evaluate possible differences between those results and the preliminary interpretation of diet based on fatty acid signatures.

Fatty acid signatures have indicated that fine-scale structure of foraging distribution of harbor seals can be discerned, and that this is due not only to localized feeding patterns in seals, but also to specific differences in prey species with size and location or habitat within PWS. Harbor seals are likely to adjust their foraging patterns to changes in abundance of local prey (Olesiuk 1993, Tollit \& Thompson 1996). Hence determining diets or changes in diets of harbor seals over time using fatty acid signatures may provide clues not only to changes in foraging patterns, but also to differences in local prey availability, predominant species size classes, and species abundance. We conclude that fatty acid signature analysis will likely result in an important contribution to understanding harbor seal foraging ecology and marine food webs in PWS, which will also likely be applicable to understanding other estuarine and marine environments. It has been proposed that one cause for the decline in some Alaskan pinniped populations may have been a change in community structure over time that resulted in an ecosystem dominated by large predatory pollock, thus making small forage fish less available to pinnipeds, especially juveniles (NRC 1996). Indeed, the ability to detect relationships between and within predators and prey on a small spatial scale suggests that fatty acid signature analysis, in combination with methods such as satellite telemetry, could begin to address such hypotheses

Acknowledgements. We thank C. Beck and J. Lassner for extensive laboratory assistance and $\mathrm{J}$. Smith for computing and statistical assistance throughout this project. We also acknowledge the assistance of R. G. Ackman in clanfying the identifications of some unusual fatty acids. A number of people assisted in the live capture of seals and collection of blubber samples and we thank them all, especially B. Fadely and J. Lewis. The biosampling program that provided samples from subsistence hunters was organized by the Alaska Native Harbor Seal Commission and supported by the 'Exxon Valdez' onl spill Trustee Council. E. Brown, M. Powell, L. Haldorson, and others kindly provided us samples of harbor seal prey. We thank W. D. Bowen for helpful comments on an earlier version of this manuscript. This study was conducted as part of the 'Exxon Valdez' Oil Spill Restoration Program, funded by the 'Exxon Valdez' Oil Spill Trustee Council. A Natural Sciences and Engmeenng Research Council (NSERC) operatung and equipment grant to S.J.I. provided additional support .

\section{LITERATURE CITED}

Ackman RG (1976) Fish oil composition. In: Objective methods for food evaluation. National Academy of Sciences Washington, DC, p 103-128

Ackman RG (1980) Fish lipids, Part 1 In: Connell JJ (ed) Advances in fish science and technology. Fishing News Books Ltd, Surrey, p 86-103

Ackman RG (1991) Application of gas-liquid chromatography to lipid separation and analysis: qualitative and quantitative analysis. In: Perkıns EG (ed) Analysis of fats, oils and lipoproteins. American Oil Chemists' Society, Champagne, IL, p 271-300

Ackman RG (1994) GLC: early developments, practical applications. INFORM 5(10):1119-1128

Ackman RG, Eaton CA (1971) Mackerel lipıds and fatty acids. Can lnst Food Technol J 4:169-174

Armstrong SG, Wyllie SG, Leach DN (1994) Effects of season and location of catch on the fatty acid compositions of some Australian fish species. Food Chem 51:295-305

Beddington JR, Beverton RJH, Lavigne DM (eds) (1985) Marine mammals and fisheries. George Allen and Unwin, London

Bigg MA, Fawcett IF (1985) Two biases in diet determination of northern fur seals (Callorhinus ursinus). In: Beddington JR, Beverton RJH, Lavigne DM (eds) Marine mammals and fisheries. George Allen and Unwin, London, p 284-291

Bjorge A (1995) Comparative habitat use and foraging behavior of harbour seals and grey seals in western Norway. Comm Meet Int Counc Explor Sea C.M. -ICES/n:1 
Bligh EG, Dyer WJ (1959) A rapid method of total lipıd extraction and purification. Can J Biochem Physiol 37:911-917

Bowen WD, Harrison GD (1996) Comparison of harbour seal diets in two inshore habitats of Atlantic Canada. Can $J$ Zool 74:125-135

Clark LA, Pregibon D (1992) Tree-based models. In: Chambers JM, Hastie TJ (eds) Statistical models. S. Wadsworth \& Brooks/Cole Advanced Books \& Software, Chapman \& Hall, New York, p 377-419

Colby RH, Mattacks CA, Pond CM (1993) The gross anatomy, cellular structure and fatty acid composition of adipose tissue in captive polar bears (Ursus maritımus). Zoo Biol $12: 267-275$

Cook HW (1985) Fatty acid desaturation and chain elongation in eucaryotes. In: Vance DE, Vance JE (eds) Biochemistry of lipids and membranes. The Benjamin/Cummings Publishing Co, Inc, Menlo Park, CA, p 181-211

Folch J, Lees M, Sloane-Stanly GH (1957) A simple method for the isolation and purification of total lipids from animal tissues. J Biol Chem 226:497-509

Fraser AJ, Sargent JR, Gamble JC, Seaton DD (1989) Formation and transfer of fatty acids in an enclosed marine food chain comprising phytoplankton, zooplankton and hernng (Clupea harengus L.) larvae. Mar Chem 27:1-18

Frost KJ, Lowry LF (1981) Trophic importance of some maxine gadoids in northern Alaska and their body-otolith size relationships. Fish Bull US 84:192-197

Frost KJ, Lowry LF (1986) Sizes of walleye pollock (Theragra chalcogrammal consumed by marine mammals in the Bering Sea. Fish Bull US 84:192-197

Frost KJ, Lowry LF (1994) Assessment of injury to harbor seals in Prince William Sound, Alaska, and adjacent areas following the Exxon Valdez oil spill. Final Rep Marine Mammal Study No. 5. State-Federal Resource Damage Assessment

Frost KJ, Lowry LF, Small. RJ, Iverson SJ (1996) Monitoring habitat use and trophic interactions of harbor seals in Prince William Sound, Alaska. Exxon Valdez Oil Spill Restoration Project Annual Report (Restoration Projects 95064). Alaska Department of Fish and Game, Division of Wildlife Conservation, Fairbanks

Frost KJ, Lowry LF, Ver Hoef J (1995) Habitat use, behavior, and monitoring of harbor seals in Prince William Sound, Alaska. Exxon Valdez Oil Spill Restoration Project Annual Report (Restoration Projects 94064 and 94320-F), Alaska Department of Fish and Game, Division of Wildlife Conservation, Fairbanks

Graeve M, Kattner G, Hagen W (1994) Diet-induced changes in the fatty acid composition of Arctic herbirorous copepods: experimental evidence of trophic markers. J Exp Mar Biol Ecol 182:97-110

Grahl-Nielsen O, Mjaavatten O (1991) Dietary influence on fatty acid composition of blubber fat of seals as determined by biopsy: a multivariate approach. Mer Biol 110: $59-64$

Harwood J, Croxall JP (1988) The assessment of competition between seals and commercial fisheries in the North Sea and the Antarctic. Mar Mamm Sci 4:13-33

Heide-Jørgensen MP, Dietz R (1995) Some characteristics of narwhal, Monodon monoceros, diving behaviour in Baffin Bay. Can J Zool 73:2120-2132

Iverson. SJ (1988) Composition, intake and gastric digestion of milk lipids in pinnipeds. PhD thesis, Univ of Maryland, College Park

Iverson SJ (1993) Milk secretion in marine mammals in relation to foraging: can milk fatty acids predict diet? Symp Zool Soc Lond 66:263-291.
Iverson S (1995) Prunciples of fatty acid signature analysis and its use in studying foraging ecology and diets of marine mammals. ICES/NAFO Symp, Role of marine mammals in the ecosystem. Halifax, NS, p 2.2

Iverson SJ, Arnould JPY, Boyd IL (1997) Milk fatty acid signatures indicate both major and minor shifts in the foraging ecology of lactating Antarctic fur seals. Can $\int$ Zool 75 : $188-197$

Iverson SJ, Frost $\mathrm{K}$ (1996) The use of fatty acid signatures to investıgate foraging ecology and food webs in Prince William Sound, Alaska: harbor seals and their prey, Exxon Valdez Oil Spill Restoration Project (No. 95064) Annual Report, Alaska Dept of Fish and Game, Fairbanks

Iverson SJ, Oftedal OT, Bowen WD, Boness DJ, Sampugna J (1995) Prenatal and postnatal transfer of fatty acids from mother to pup in the hooded seal (Cystophora cristata). J Comp Physiol 165:1-12

Iverson SJ, Sampugna J, Oftedal OT (1992) Positional specificity of gastric hydrolysis of long-chain $n-3$ polyunsaturated fatty acids of seal milk triglycerides. Lipids 27:870-878

Jobling $M$, Brieby $A$ (1986) The use and abuse of fish otoliths in studies of feeding habits of marine piscivores. Sarsia $71: 265-274$

Johnson RA, Wichern DW (1992) Applied multivariate statistical analysis, 3rd edn. Prentice-Hall, Inc, Englewood Cliffs, NJ

Kirsch PE, Iverson SJ, Bowen WD (1995) Diet composition based on fatty acid signatures: captive feeding experiments on harp seals and grey seals. In: Abstr, Eleventh Bienn Conf Biol Marine Mamm. Orlando, FL, p 62

Klungsoyr J, Tilseth S, Wilhelmsen S, Falk-Petersen S, Sargent JR (1989) Fatty acid composition as an idicator of food intake in cod larvae Gadus morhua from Lofoten, Northern Norway. Mar Biol 102:183-188

Koopman HN, Iverson SJ, Gaskin, DE (1996) Stratifıcatıon and age-related differences in blubber fatty acids of the male harbour porpoise (Phocoena phocoena). J Comp Physiol B 165:628-639

Lalli CM, Parsons TR (1993) Biological oceanography. Pergamon Press, Oxford

Lee RF, Nevenzel JC, Paffenhöfer GA (1971) Importance of wax esters and other lipids in the marine food chain phytoplankton and copepods. Mar Biol 9:99-108

Loughlin TR, Perlov AS, Vladimirov VA (1992) Range-wide survey and estimation of total numbers of Steller sea lions in 1989. Mar Mamm Sci 8:220-239

Martin FD, Wright DA, Means JC (1984) Fatty acids and starvation in larval striped bass (Morone saxatilss). Comp Biochem Physiol (77B) (4):785-790

Merrick RL, Loughlin TR, Antonelıs GA, Hill R (1994) Use of satellite-linked telemetry to study Steller sea Iion and northern fur seal foraging. Polar Res 13:105-114

Navarro JC, McEvoy LA, Amat F, Sargent JR (1995) Effects of diet on fatty acid composition of body zones in larvae of the sea bass Dicentrarchus labrax: a chemometric study. Mar Biol 124:177-183

NRC (National Research Council) (1996) The Bering Sea ecosystem. Committee on the Bering Sea, National Academic Press, Washington, DC

Niebauer HJ, Royer TC. Weingartner TJ (1994) Circulation of Prince William Sound, Alaska. J Geophys Res 99: $14113-14126$

Olesiuk PF (1993) Annual prey consumption by harbor seals (Phoca vitulina) in the Straight of Georgia, British Columbia. Fish Bull US 91:491-515

Olesiuk PF, Bigg MA, Ellis GM (1990) Recent trends in the 
abundance of harbour seals, Phoca vitulina, in British Columbia. Can J Fish Aquat Sci 47:992-1003

Paradis M, Ackman RG (1976) Localization of a source of marine odd chain length fatty acids. 1. The amphipod Pontoporeia femorata (Krøyer). Lipids 11:863-870

Payne PM, Selzer LA (1989) The distribution, abundance and selected prey of the harbor seal, Phoca vitulina concolor, in southern New England. Mar Mamm Sci 5:173-192

Pereya WT, Reeves JE, Bakkala RG (1976) Demersal fish and shellfish resources of the eastern Bering sea in the baseline year 1975. Prog Rep OSCEAP RU No. 175, October. NOAA, US Dept of Commerce and Bur Land Mgmt, US Dept of the Interior, Northwest and Alaska Fish Center

Plerce GJ, Boyle PR (1991) A review of methods for diet analysis in piscivorous marine mammals. Oceanogr Mar Biol Annu Rev 29:409-486

Pitcher KW (1980a) Food of the harbor seal, Phoca vitulina richardsi, in the Gulf of Alaska. Fish Bull US 78:544-549

Pitcher KW (1980b) Stomach contents and feces as indicators of harbor seal, Phoca vitulina, foods in the Gulf of Alaska. Fish Bull US 78:797-798

Pitcher KW (1990) Major decline in number of harbor seals, Phoca vitulina richardsi, on Tugidak Island, Gulf of Alaska. Mar Mamm Sci 6:121-134

Pitcher KW, MCAllister DC (1981) Movements and haulout behavior of radio-tagged harbor seals, Phoca vitulina. Can Field-Nat 95:292-297

Pond CM, Mattacks CA, Gilmour I, Johnston MA, Pillinger CT (1995) Chemical and carbon isotopic composition of fatty acids in adipose tissue as indicators of dietary history in wild arctic foxes (Alopex lagopus) on Svalbard. J Zool Lond 236:611-623

Reidinger RF, Labows JN, Fellows D, Mason JR (1985) Fatty acid composition of adipose tissue as an indicator of diet: a preliminary assessment. J Wildl Mgmt 49:170-177

Rouvinen K, Kiiskinen I (1989) Influence of dietary fat source on the body fat composition of mink (Mustela vison)

This article was submitted to the editor and blue fox (Alopex lagopus). Acta Agric Scand 39: $279-288$

Sargent JR, Parkes RJ, Mueller-flarvey I, Henderson RJ (1988) Lipid biomarkers in marine ecology. In: Sleigh MA (ed) Microbes in the sea. Ellis Horwood, Ltd, Chichester, p $119-138$

Shelton PA, Stenson GB, Sjare B, Warren WG (1995) Model estimates of harp seal numbers at age for the northwest Atlantic. DFO Atlantic Fisheries Res Doc 95/21

Smith SJ, Iverson SJ, Bowen WD (1997) Fatty acid signatures and classification tress: new tools for investigating the foraging ecology of seals. Can J Fish Aquat Sci (in press)

Stewart BSS, Yochem P (1994) Ecology of harbor seals in the southern California bight. In: Halvorson WL, Maender GJ (eds) The Fourth California Islands Symposium: update on the status of resources. Santa Barbara Museum of Natural History, CA, p 123-134

St. John MA, Lund T (1996) Lipid biomarkers: linking the utilization of frontal plankton biomass to enhanced condition of juvenile North Sea cod. Mar Ecol Prog Ser 131:75-85

Sturdevant MV (1996) Diet overlap of forage fish species. Appendix C-1 In: Duffy DC (compiler) APEX: Alaska Predator Ecosystem Experiment. Exxon Valdez Oil Spill Restoration Project Annual Report (Restoration Project 95163). Alaska Natural Heritage Program, University of Alaska, Anchorage

Thompson PM, Miller D (1990) Summer foraging activity and movements of radio-tagged common seals (Phoca vitulina L.) in the Moray Firth, Scotland. J Appl Ecol 27:492-501

Tollitt DJ, Thompson PM (1996) Seasonal and between-year variations in the diet of harbour seals in the Moray Firth, Scotland. Can J Zool 74:1110-1121

Venables W. Ripley B (1994) Modern applied statistics with S-Plus. Springer Verlag. Heidelberg

Walters RA, Josberger EG, Driedger CL (1988) Columbia Bay, Alaska: an 'upside down' estuary. Estuar Coast Shelf Sci $26: 607-617$

Manuscript first received: September 4, 1996 Revised version accepted: February 20,1997 